\title{
Combined dust detection algorithm by using MODIS infrared channels over East Asia
}

\author{
Sang Seo Park ${ }^{a}$, Jhoon Kim ${ }^{\mathrm{a}, *}$, Jaehwa Lee ${ }^{\mathrm{a}, 1,2}$, Sukjo Lee ${ }^{\mathrm{b}}$, Jeong Soo Kim ${ }^{\mathrm{b}}$, Lim Seok Chang ${ }^{\mathrm{b}}$, Steve Ou ${ }^{\mathrm{c}}$ \\ ${ }^{a}$ Global Environment Laboratory/Department of Atmospheric Science, Institute of Earth Atmosphere Astronomy (IEAA), Yonsei University, Seoul, Republic of Korea \\ ${ }^{\mathrm{b}}$ National Institute of Environment Research, Ministry of Environment, Incheon, Republic of Korea \\ c JIFRESSE, UCLA, Los Angeles, CA, USA
}

\section{A R T I C L E I N F O}

\section{Article history:}

Received 19 October 2012

Received in revised form 17 September 2013

Accepted 18 September 2013

Available online 19 November 2013

\section{Keywords:}

MODerate resolution Imaging

Spectroradiometer (MODIS)

Dust detection

Dust

East Asia

\begin{abstract}
A B S T R A C T
A new dust detection algorithm is developed by combining the results of multiple dust detection methods using IR channels onboard the MODerate resolution Imaging Spectroradiometer (MODIS). Brightness Temperature Difference (BTD) between two wavelength channels has been used widely in previous dust detection methods. However, BTD methods have limitations in identifying the offset values of the BTD to discriminate clear-sky areas. The current algorithm overcomes the disadvantages of previous dust detection methods by considering the Brightness Temperature Ratio (BTR) values of the dual wavelength channels with 30-day composite, the optical properties of the dust particles, the variability of surface properties, and the cloud contamination. Therefore, the current algorithm shows improvements in detecting the dust loaded region over land during daytime. Finally, the confidence index of the current dust algorithm is shown in $10 \times 10$ pixels of the MODIS observations. From January to June, 2006, the results of the current algorithm are within 64 to $81 \%$ of those found using the fine mode fraction (FMF) and aerosol index (AI) from the MODIS and Ozone Monitoring Instrument (OMI). The agreement between the results of the current algorithm and the OMI AI over the non-polluted land also ranges from 60 to $67 \%$ to avoid errors due to the anthropogenic aerosol. In addition, the developed algorithm shows statistically significant results at four AErosol RObotic NETwork (AERONET) sites in East Asia.
\end{abstract}

(c) 2013 Elsevier Inc. All rights reserved.

\section{Introduction}

Wind-blown dust is one of the important trans-boundary pollutants affecting air quality over East Asia in spring, with its main sources being the Gobi and Taklamakan deserts located in China and Mongolia. Dust is lifted up in dry weather condition over hot desert surfaces and then is transported to surrounding regions by strong winds, which results in air quality problems and significant reductions in visibility (Darmenova, Sokolik, \& Darmenov, 2005). During the transport, Asian dust is partly mixed with anthropogenic aerosols over East Asia due to abundant pollutant sources (Chu et al., 2005).

The chemical and physical properties of dust aerosol affect the radiation fields over wide wavelength regions from ultraviolet (UV) to infrared (IR), while those of anthropogenic aerosols have minor effect on the IR wavelengths due to their small particle size. By using these radiative properties, several optical observation techniques have been

\footnotetext{
* Corresponding author at: Institute of Earth, Astronomy, and Atmosphere, Brain Korea 21 Program, Department of Atmospheric Sciences, Yonsei University, Seoul, Republic of Korea. Tel.: + 8222123 5682; fax: +822365 5163 .

1 NASA Goddard Space Flight Center, Greenbelt, MD, U.S.A.

2 Earth System Science Interdisciplinary Center, University of Maryland, College Park, MD, U.S.A.
}

developed to detect and quantify dust aerosols. The AErosol RObotic NETwork (AERONET), a federated ground-based observation network, provides various optical properties of aerosols, including the spectral aerosol optical depth (AOD), refractive indices, and size distribution in the UV through near-infrared wavelength ranges over the globe (Holben et al., 1998).

Satellite remote sensing also provides global information on aerosol optical properties by using shortwave channels during daytime over both land and ocean (e.g. Hsu, Tsay, King, \& Herman, 2004; Kim et al., 2007; Lee, Kim, Yang, \& Hsu, 2012; Lee et al., 2010; Levy, Remer, Mattoo, Vermote, \& Kaufman, 2007; Remer et al., 2005). In addition, satellite observation in thermal IR wavelengths has the advantage of allowing dust observation at nighttime in addition to daytime (c.f. Ackerman, 1997; Chomette, Legrand, \& Marticorena, 1999; Hansell et al., 2007; Pierangelo, Chedin, Heilliette, Jacquinet-Husson, \& Armante, 2004), which allows more frequent monitoring of dust transport. The optical properties of dust at the IR wavelengths are related to the spectral refractive indices of their combined minerals and their size distribution (Sokolik \& Toon, 1999; Sokolik, Toon, \& Bergstrom, 1998). Ackerman (1997) reported that the real (i.e. scattering properties) and imaginary (i.e. absorption properties) parts of complex refractive indices for quartz are strongly dependent on wavelength in the thermal IR (8-12 $\mu \mathrm{m})$ and hence can be useful for detecting dust with a large sand component. Ackerman (1997) also showed the spectral variability of the imaginary 


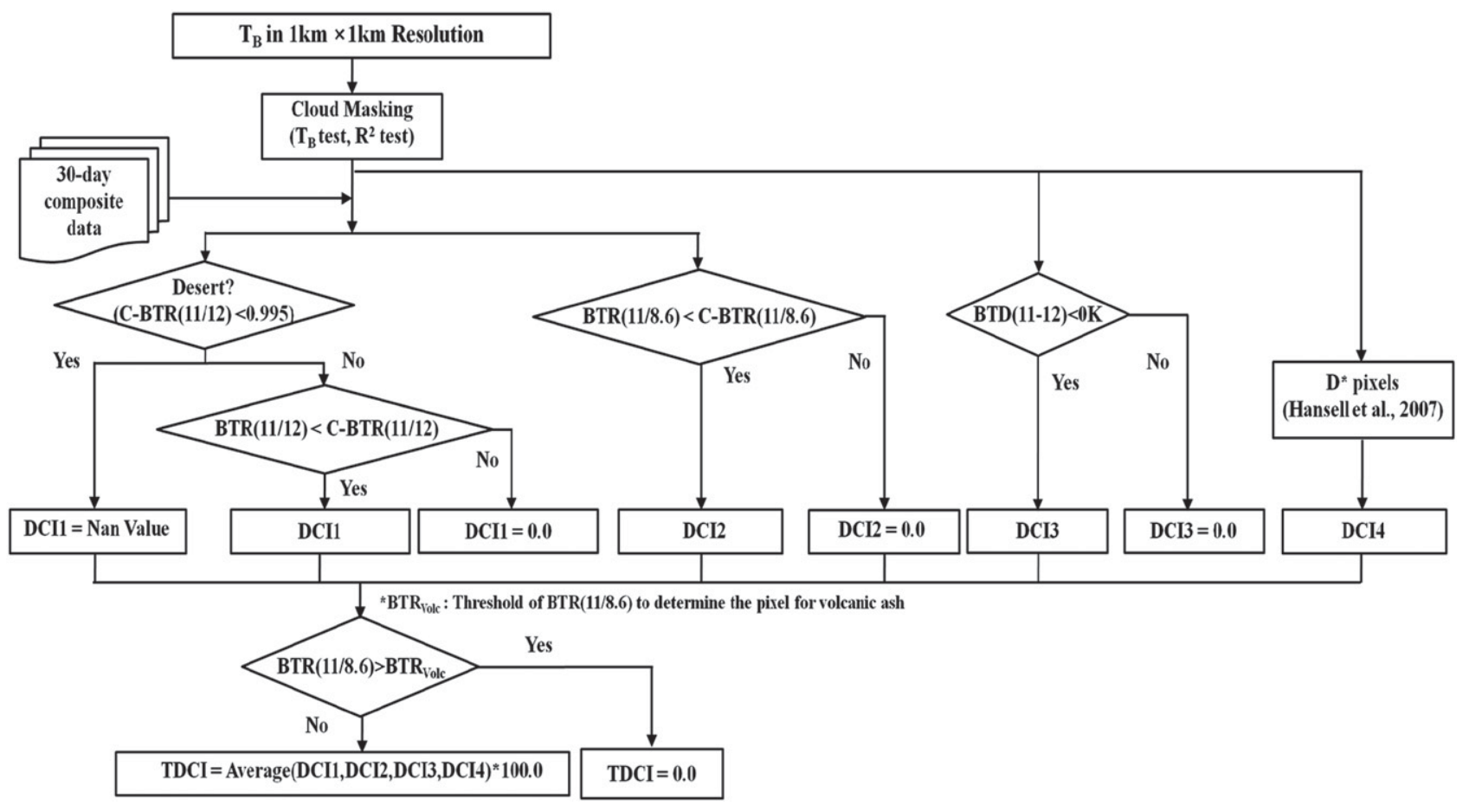

Fig. 1. Flowchart of the combined IR dust detection algorithm.

term for common dust components such as hematite and ammonium sulfate in the thermal IR region. More recently, Hudson, Gibson, Young, Kleiber, and Grassian (2008) illustrated that simulations considering non-spherical particles of dust in the thermal IR better reproduce experimental extinction spectra for common components of dust aerosols.

Based on the optical properties of dust, dust detection methods have been developed by using thermal IR channels. Shenk and Curran (1974) investigated a dust detection method for the Saharan dust using the temperature change of the IR channels observed by the Nimbus-4 satellite. They showed that the dust plume changes the temperature contrast between the surface and atmosphere. Ackerman (1997) introduced a method using a combination of the Brightness Temperature (BT) change for multiple channels. The BT is dependent on the optical properties of dust, which is influenced by the chemical composition, size distribution (Merchant, Embury, Le Borgne, \& Bellec, 2006; Sokolik et al., 1998), and layer heights (Pierangelo et al., 2004). For these reasons, previous studies introduced the algorithms based on the Brightness Temperature Difference (BTD) between two wavelength channels (e.g. Ackerman, 1997; Darmenov \& Sokolik, 2005). Moreover, additional channels were used (e.g. Hansell et al., 2007; Miller, 2003; Roskovensky \& Liou, 2005), where the correction factors and fixed threshold values were employed to minimize the errors due to different properties of surface and dust minerals. The results of these methods, however, were dependent on changes of the correction factors. Baddock, Bullard, and Bryant (2009) presented the advantages of simultaneously using the results of several dust detection methods, to identify the dust-laden area over land in Australia. This previous study showed that dust pixels are consistently detected near the source regions for several cases using the results of the three dust detection methods.

In this study, we propose a new dust index by combining four different dust detection methods by using the Dust Confidence Index (DCI). To estimate the DCI, a new test using Brightness Temperature Ratio (BTR) between two wavelength channels is added to distinguish between the dust and surface signals more accurately, in addition to the widely used dust detection methods including BTD. The combination of several methods results in the improvement in accuracy and reliability of dust detection. The BTR method is also applied to minimize the errors due to the emissivity spectra difference for various surface types. By combining several tests together with the newly introduced test, the overall performance of dust detection is improved. These results are expected to provide more quantitative information in detecting dust from satellite imagery. The paper is organized as follows. Section 2 discusses the data used, while Section 3 presents an overview of the algorithm. Detection results and validation are given in Section 4 and finally a summary and conclusion are presented in Section 5 .

\section{Dataset}

IR bands of the MODerate resolution Imaging Spectroradiometer (MODIS) onboard Aqua satellite are used to detect dust over East Asia. MYD02, level 1B calibrated radiance data, and MYD03, geo-location data, are used in this study. MODIS is a 36-band spectrometer covering spectral range from the visible to infrared onboard sun synchronous satellites, with an equatorial crossing time of 1:30 PM for Aqua. The IR bands have a spatial resolution of $1 \mathrm{~km} \times 1 \mathrm{~km}$ (http://modis.gsfc. nasa.gov/about/specifications.php). There are 16 bands in IR (bands 20 to 36, except band 26), including the atmospheric window channels, bands $29(8.400-8.700 \mu \mathrm{m}), 31(10.78-11.28 \mu \mathrm{m})$ and 32 (11.77$12.27 \mu \mathrm{m})$. Most of the signals for the three bands in the atmospheric window are from the surface (cf. Tang \& Li, 2008). Therefore, the Brightness Temperatures (BTs) of these three bands are used to detect dust effectively, because the dust layer is mostly located in the lower-half of the troposphere. Among the three bands, however, band 29 is influenced by the weak absorption of sulfur dioxide. For this reason, bands 31 and 32 are used as the primary, and band 29 is used as an ancillary band. In addition to the conventional method for screening clouds by utilizing band 31 , a water vapor absorption band (band $28,7.175-7.475 \mu \mathrm{m}$ ) is used to improve the cloud masking. In this study, the analysis area was selected over East Asia, defined by the area from $100^{\circ} \mathrm{E}$ to $160^{\circ} \mathrm{E}$ in longitudes, and from $25^{\circ} \mathrm{N}$ to $60^{\circ} \mathrm{N}$ in latitudes. The MODIS IR data from Aqua are used for the period from January to June, 2006.

\section{Algorithm}

The characteristics of dust minerals affect the radiative spectra directly through emissivity, particle size, and refractive index (e.g. Caquineau, 
Gaudicet, Gomes, \& Legrand, 2002; Sokolik et al., 1998). For this reason, Darmenov and Sokolik (2005) showed the different thresholds of BTD between 11 and $12 \mu \mathrm{m}$, ranging from -1.0 to $0.5 \mathrm{~K}$, with regard to source regions. Seemann, Borbas, Knuteson, Stephenson, and Huang (2008) also showed that the emissivity structure in the IR wavelength range changed based on the variation of surface type. Therefore, resolving variations of the mineralogical properties of dust aerosol and the surface type are essential to improve dust detection from satellite. In this study, threshold values are defined by taking into consideration the spatial and temporal dependence to reflect the effects of these variations. In addition, new cloud masking techniques using the IR bands are implemented to minimize the effect of cloud contamination on dust detection.

\subsection{Dust detection methods}

Satellite observed BT $\left(T_{B}\right)$ is a function of surface temperature $\left(T_{S}\right)$ and emissivity, $\varepsilon(\lambda)$, depending on the wavelength, $\lambda$. However, in general, surface temperature $\left(T_{S}\right)$ is independent of the wavelength.

BTD is generally defined by the difference of the BT between two wavelengths $\left(\lambda_{1}\right.$ and $\left.\lambda_{2}\right)$ so that $\operatorname{BTD}\left(\lambda_{1}-\lambda_{2}\right)$ can be expressed as follows:

$\operatorname{BTD}\left(\lambda_{1}-\lambda_{2}\right)=\mathrm{T}_{\mathrm{B}}\left(\lambda_{1}\right)-\mathrm{T}_{\mathrm{B}}\left(\lambda_{2}\right)$

a

\section{BTR(11/12) 03/11/2006}

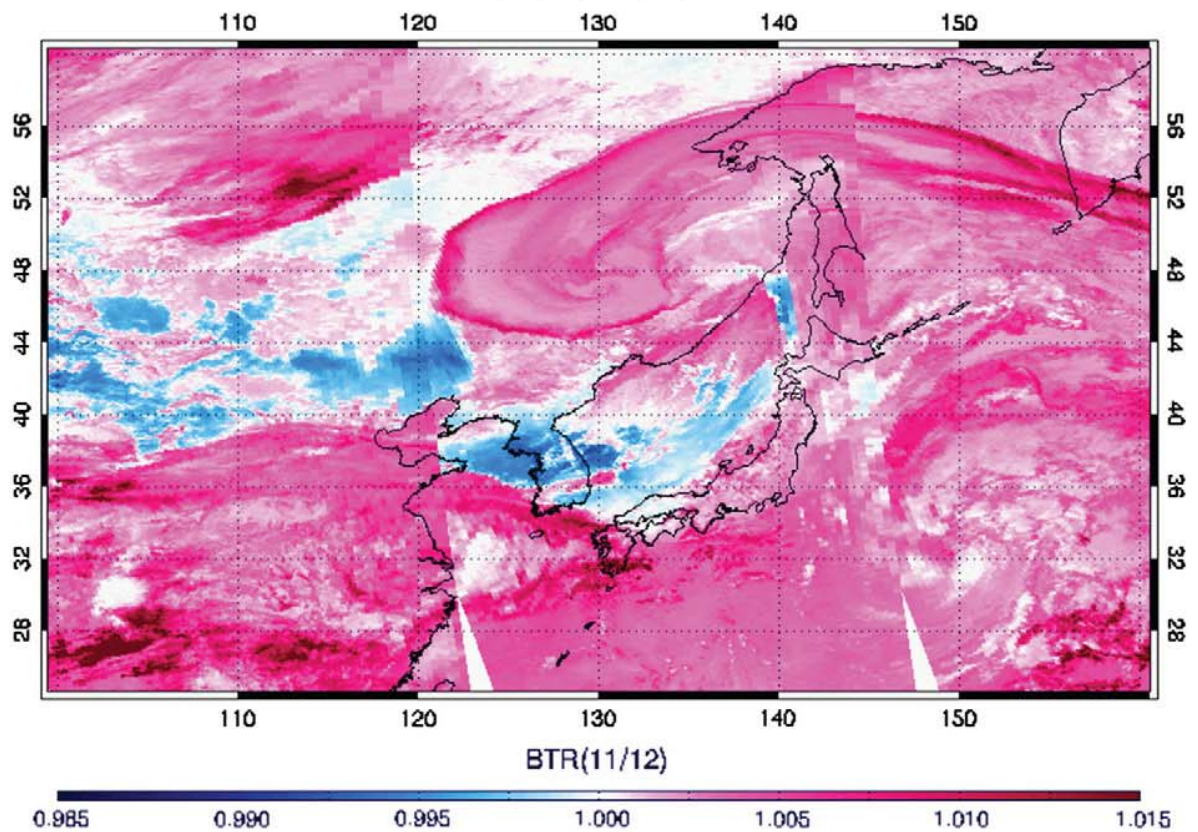

b

\section{C-BTR(11/12) 03/11/2006}

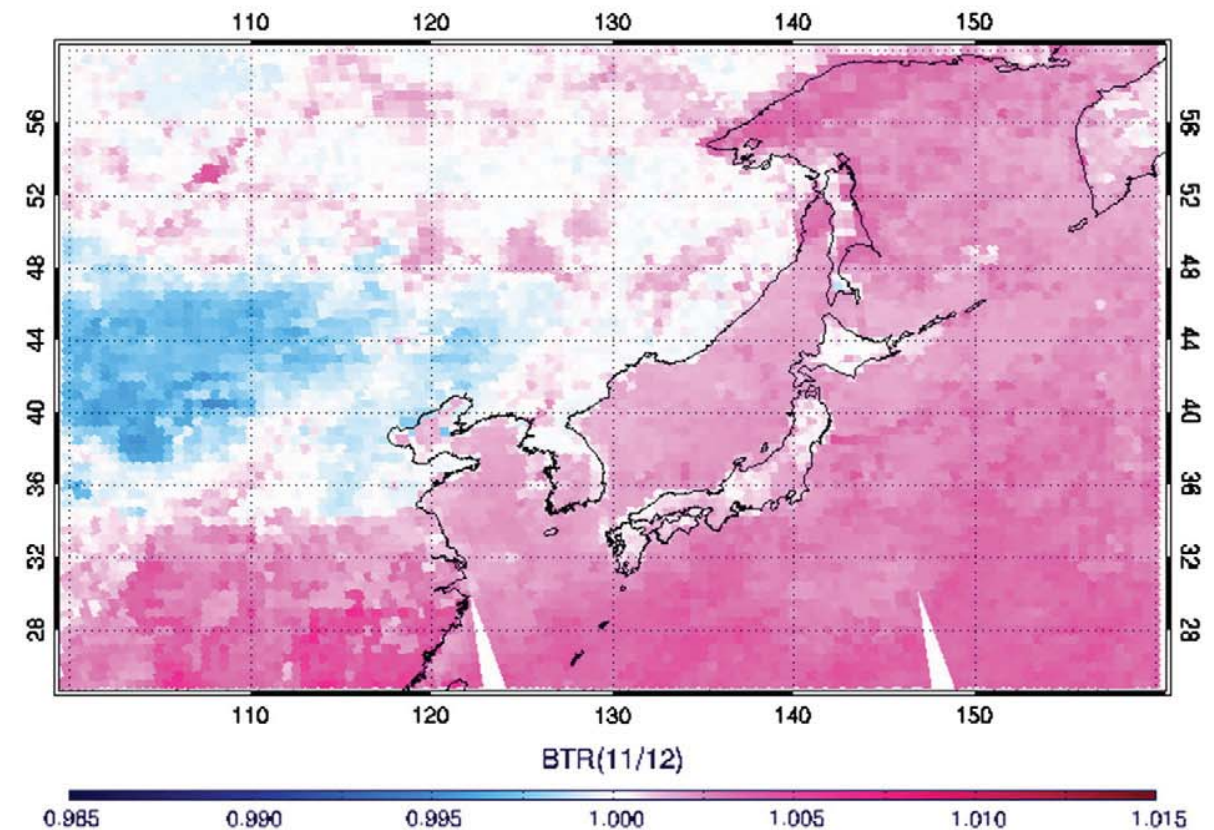

Fig. 2. (a) BTR(11/12), (b) C-BTR(11/12), and (c) difference between observed BTR(11/12) and C-BTR(11/12) on March 11, 2006 over East Asia. 


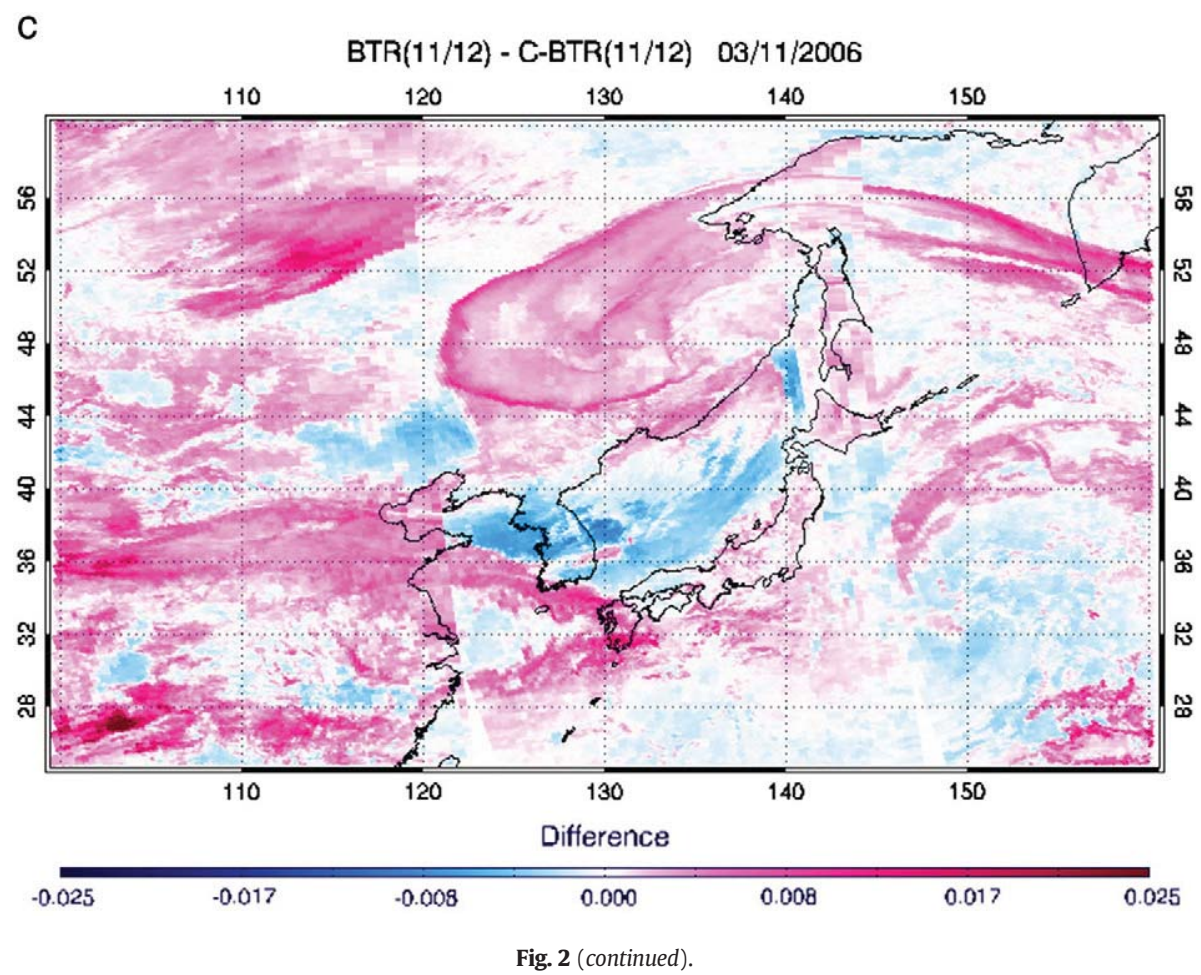

The BTD method has been used widely when estimating the difference in the emissivity between two wavelengths in order to identify the dust signals. However, the BTD is dependent not only on the emissivity change, but also on the surface temperature. The emissivity of surface remains almost constant throughout the year as shown in the results from the IR spectral emissivity database based on the MODIS product (http://cimss.ssec.wisc.edu/iremis). However, annual and diurnal variations of surface temperature are $30 \mathrm{~K}$ and $15 \mathrm{~K}$ over East Asia, respectively (Wang \& Lu, 2006), which affect the respective BTD values by $10 \%$ and $5 \%$. For this reason, the BTR value is introduced to minimize errors due to the surface temperature variation in this study. BTR is defined as a ratio of the BT between two wavelengths, which can be expressed as follows:

$\operatorname{BTR}\left(\lambda_{1} / \lambda_{2}\right)=\mathrm{T}_{\mathrm{B}}\left(\lambda_{1}\right) / \mathrm{T}_{\mathrm{B}}\left(\lambda_{2}\right)$.

Therefore, zero values of BTD correspond to 1 in BTR, and negative (or positive) BTD values correspond to values that are lower (or higher) than 1 in BTR.

In this study, the dust detection algorithm is constructed by combining a BTD test, two BTR tests, and the $\mathrm{D}^{*}$-parameter test developed by Hansell et al. (2007). The BTD test uses a fixed threshold to determine

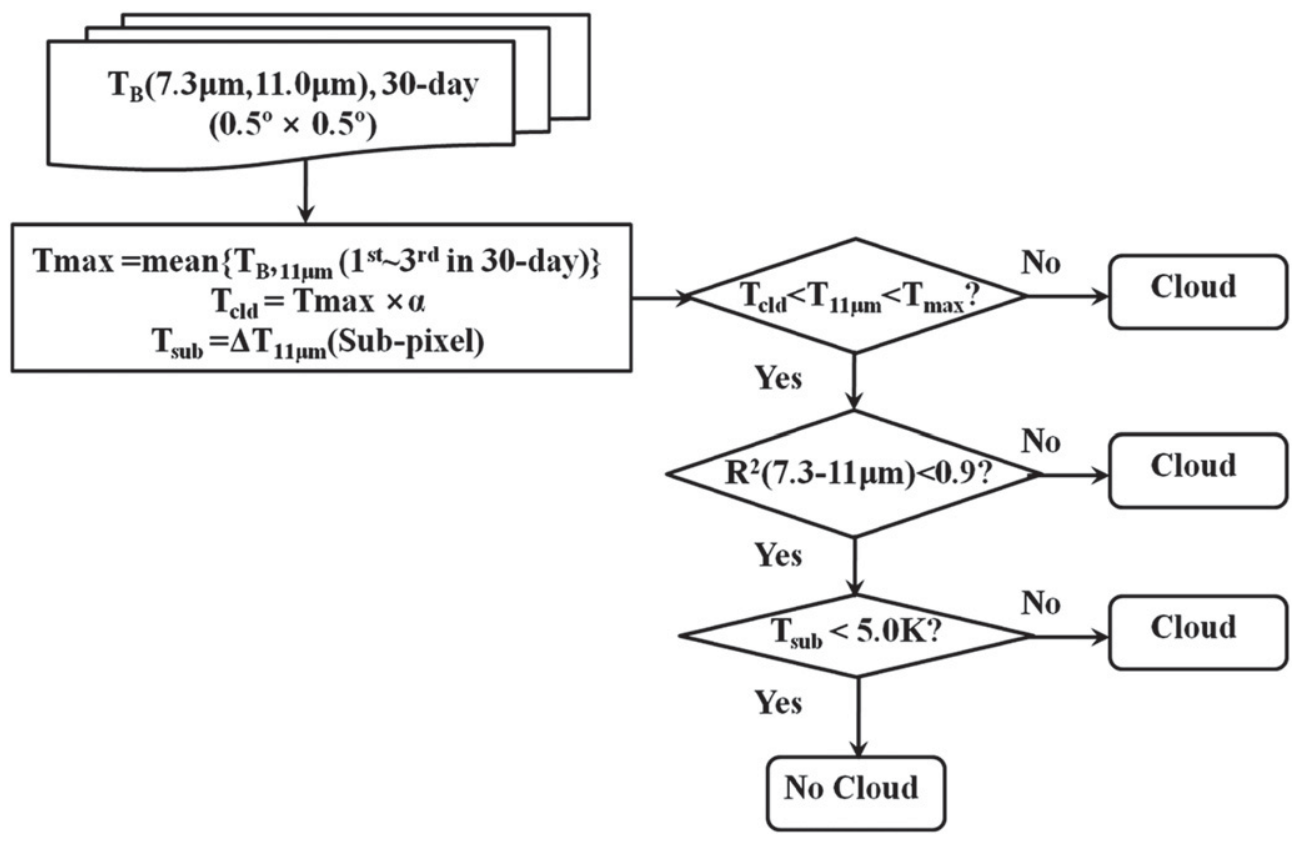

Fig. 3. Flowchart of cloud masking. 
a Cloud $04 / 08 / 2006$

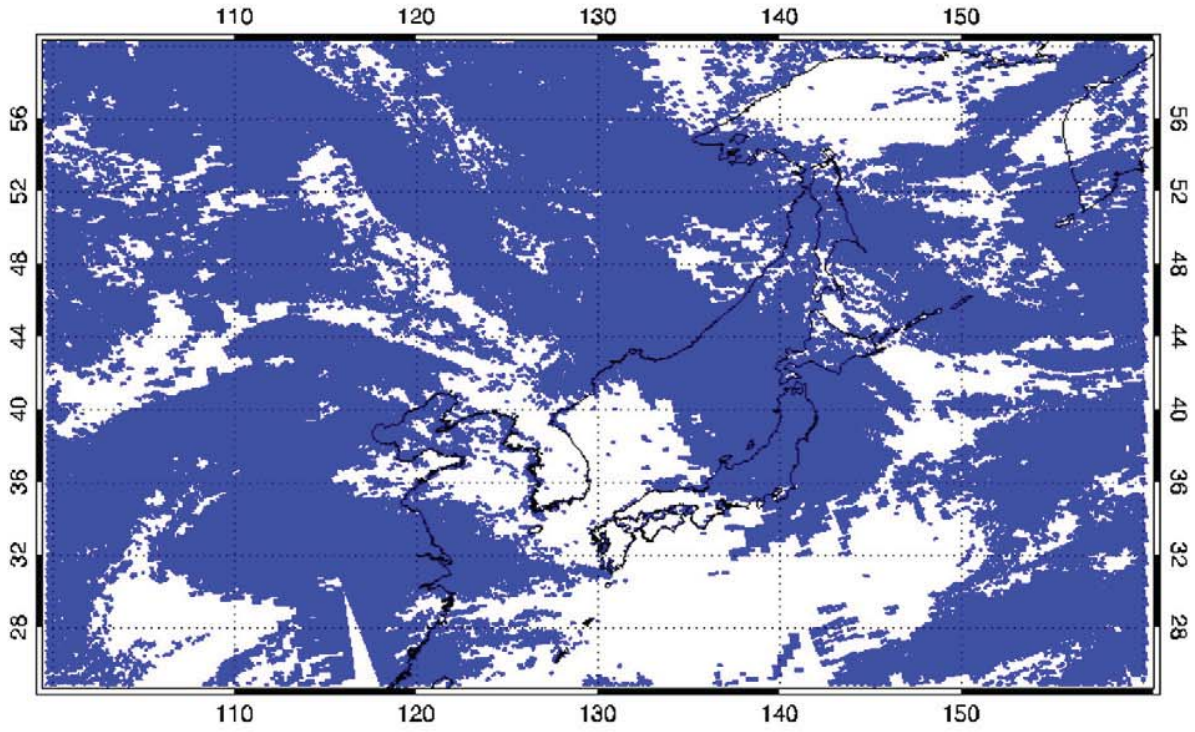

b

Aqua MODIS RGB - 04/08/2006

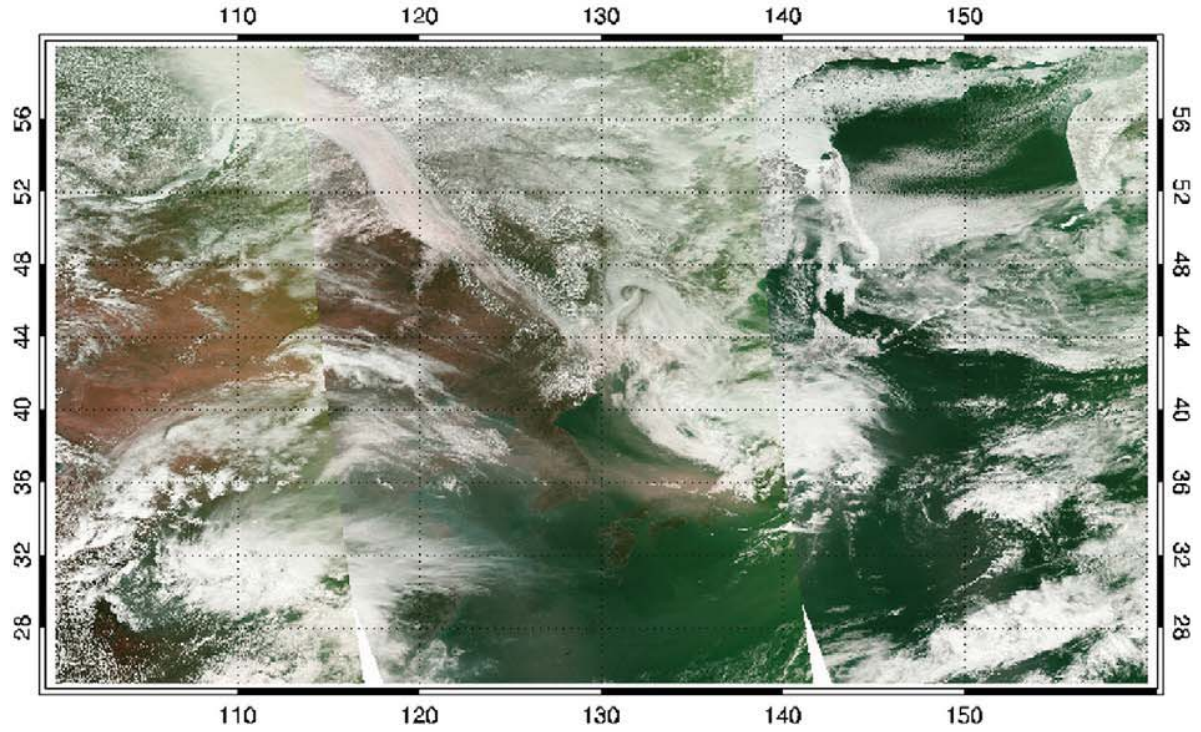

Fig. 4. (a) The result of cloud masking using BT(11), $\mathrm{R}^{2}$, and BT(11)-variation tests and (b) MODIS RGB image on April 8, 2006.

dust pixels. The two BTR tests use spatially different thresholds to consider the surface characteristics. These tests use wavelength pairs of $11 \mu \mathrm{m} / 12 \mu \mathrm{m}$, and $11 \mu \mathrm{m} / 8.6 \mu \mathrm{m}$, respectively. The $\mathrm{D}^{*}$-parameter test, which is basically a combination of the BTDs for two different wavelength pairs, is used to reduce the effect of cloud contamination.

Here, we introduce and calculate the DCI for each of the aforementioned dust detection method. The respective $\mathrm{DCI}$ is a normalized confidence level of each test, and therefore represents the confidence in dust detection for each method by scaling the value linearly between the clear sky and dusty conditions. The total DCI (TDCI), as a mean of the all DCIs, detects the pixels with dust, by comparing them with the criterion. The flowchart of the algorithm is represented in Fig. 1. The details of the flowchart are provided below.

\subsubsection{BTD(11-12) method}

This method was introduced by Shenk and Curran (1974) for the first time, and has been used widely for dust detection. BTD(11-12) is defined by a difference in the BT at 11 and $12 \mu \mathrm{m}$, which shows negative values for dust-laden areas. In contrast, the BTD(11-12) is known to show positive values for non-dust and cloud-covered areas. For this reason, many previous studies used the negative value of $\operatorname{BTD}(11-12)$ for dust detection (e.g.Ackerman, 1997; Ackerman et al., 2002; Hansell et al., 2007). However, the negative BTD(11-12) can be also observed over volcanic ash particles occurring at high altitudes (Prata, 1989), or over sulfate aerosol (Watson et al., 2004), which can potentially generates errors in discriminating dust. In addition, the spectral changes of surface emissivity for the different surface type affect the BTD values over land in particular. Therefore, the detection results are more reliable over ocean or for the case of strong dust events.

\subsubsection{0-day composite BTR (C-BTR)(11/12) method}

Basically, C-BTR(11/12) method is similar to the BTD(11-12) method except that BTR(11/12) is used as a reference value to determine the "clear" regions, which are not significantly influenced by clouds and/or 
a

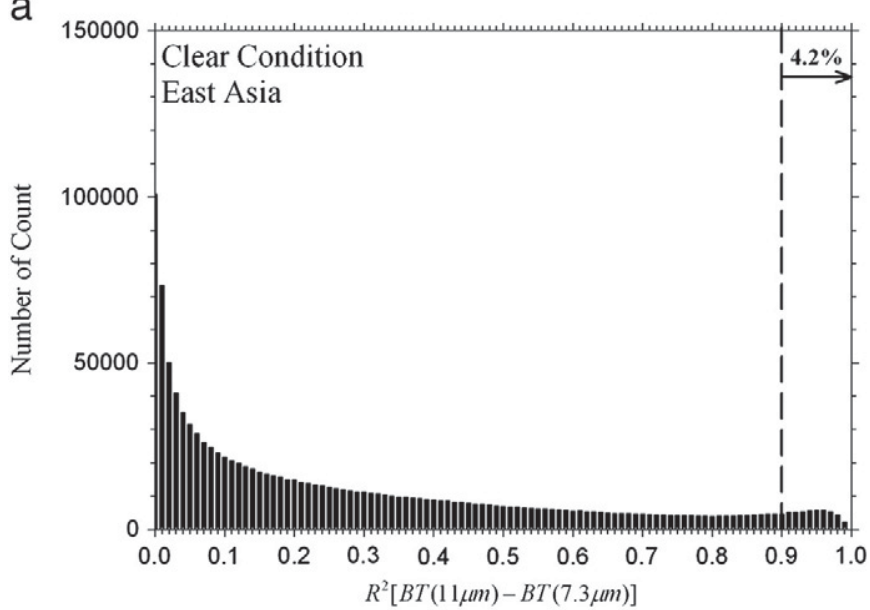

b

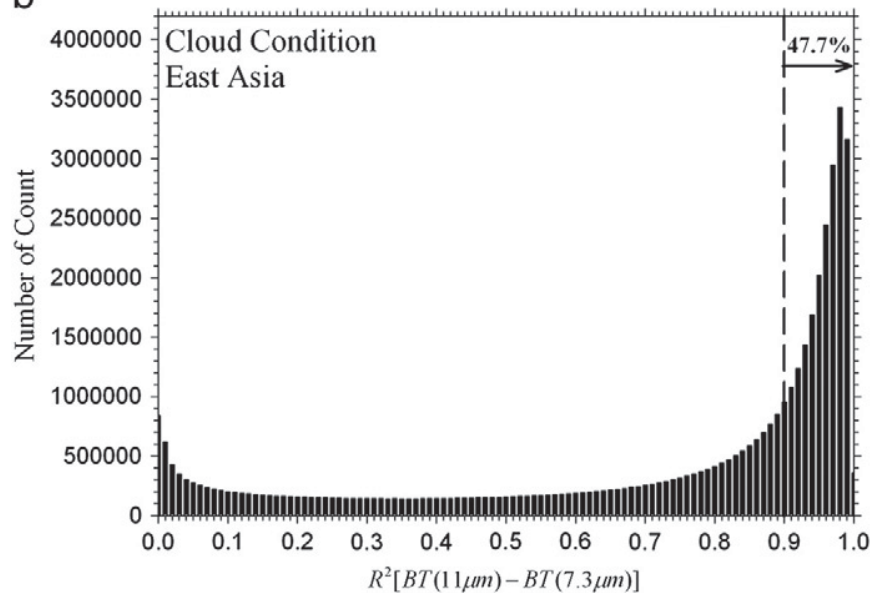

Fig. 5. Count distribution of determination coefficient $\left(R^{2}\right)$ of BT between 7.3 and $11 \mu \mathrm{m}$ (a) for clear and (b) cloudy condition.

dust. A clear reference scene defined by the maximum BT at $11 \mu \mathrm{m}$ averaged over each gridded area $\left(0.5^{\circ} \times 0.5^{\circ}\right)$ is selected within a 30day window that proceeds the day of interest. To determine the reference value, BTR(11/12), on a clear day without considerable dust events and clouds, is selected for the day with the maximum BT at $11 \mu \mathrm{m}$ in each gridded area of $0.5^{\circ} \times 0.5^{\circ}$ for the previous 30 days. Because most of the emissivity from the surface within a 30-day period is invariable from the IR spectral emissivity database, the effect of the emissivity change is negligible. Therefore, the BTR(11/12) on the selected day at each grid point is defined and compiled as the clear-sky C-BTR(11/12). The DCI of the BTR(11/12) test, at a given grid, is calculated by the difference between the current BTR(11/12) and C-BTR(11/12). Note that the reference day can be different from one grid to another because the day of maximum BT(11) is affected by different characteristics of cloud contamination and surface condition, etc. Fig. 2 shows an example of the BTR(11/12), C-BTR(11/12) and difference between the two for a dust case on March 11, 2006. The BTR(11/12) values are lower than 1 over the dust region. However, most of the region with the BTR(11/12) lower than 1 is also affected by the signal from the surface as shown in the result for the C-BTR(11/12). The classic BTD(11-12) would have provided false detection for the dust in this region. Fig. 2(c) shows the difference between BTR(11/12) and C-BTR(11/12), where the negative values coincide with the dust region as the surface signals are removed by the C-BTR(11/12). Therefore, the C-BTR method allows us to distinguish the detected BTR signal of dust layers from the surface emission, by taking the difference between the BTR and the C-BTR.
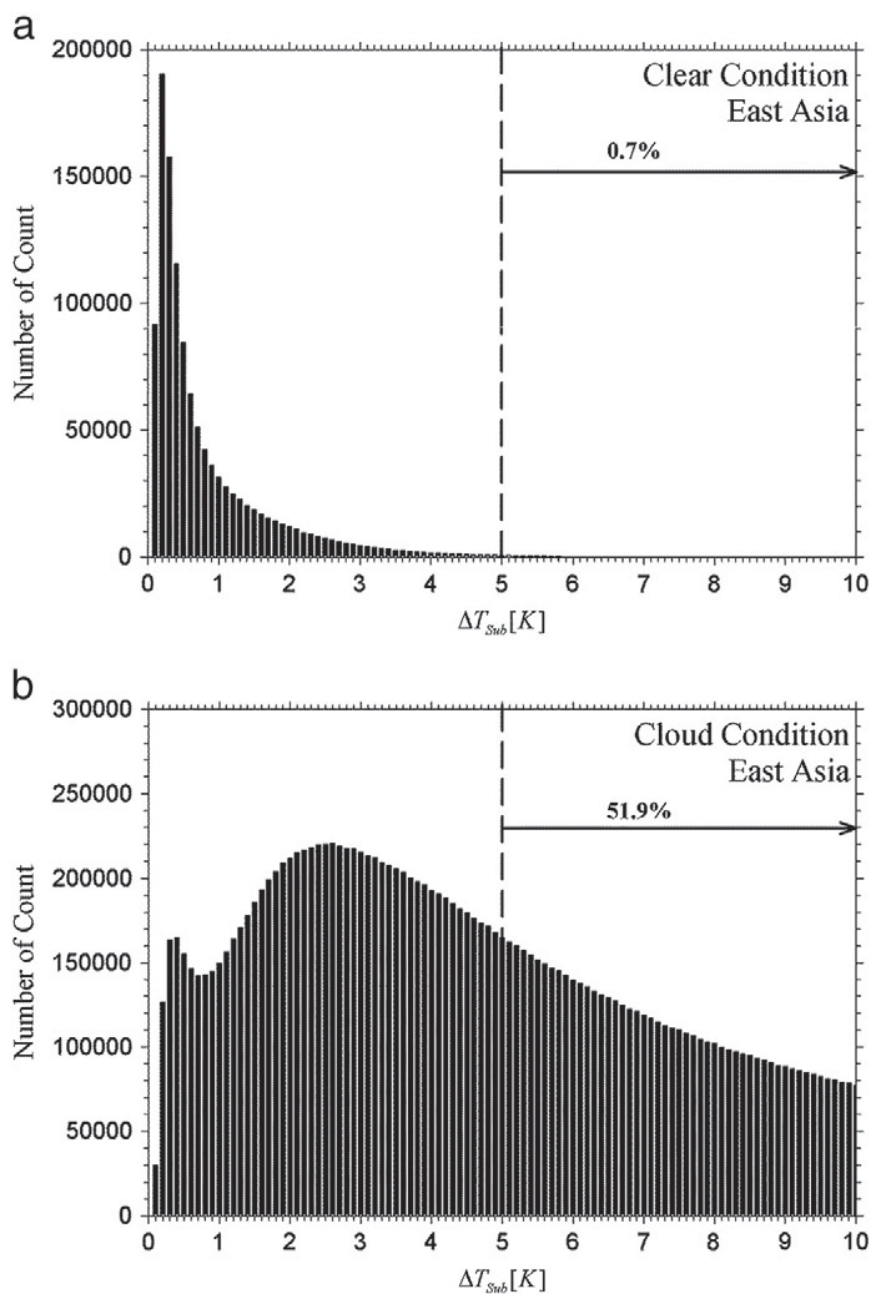

Fig. 6. Count distribution of BT(11) variation (a) for clear and (b) cloudy conditions.

The emissivity spectra of dust and desert surface have similar tendencies between 11 and $12 \mu \mathrm{m}$ because the composition of the desert surface is similar to that of floating dust. Therefore, it is difficult to distinguish dust over the desert surface from the desert surface itself. For this reason, we classify desert surfaces by using the C-BTR(11/12), so that no DCI is calculated over the selected area. The desert surface can be distinguished by its low C-BTR(11/12) values, because of the rapidly varying spectral absorption features of surface materials near 10 to $11 \mu \mathrm{m}$ compared to those at 11 to $12 \mu \mathrm{m}$ (Elachi \& van Zyl, 2006). The threshold of the C-BTR(11/12) is set as 0.995, because all of the surface types except for desert and savanna (mostly located in the tropics) show the emissivity ratio between 11 and $12 \mu \mathrm{m}[\varepsilon(11) / \varepsilon(12)]$ larger than 0.995 based on the work from Chen, Sun-Mack, Minnis, Young, and Smith (2002).

\subsubsection{C-BTR(11/8.6) method}

De Paepe and Dewitte (2009) showed that BTD(11-8.6) has the advantage of detecting dust over bright surfaces. An emissivity of the bright surface near $8.6 \mu \mathrm{m}$ shows a low value due to the reststrahlen band of mineral compositions, and its band intensity increases with increasing particle size. Meanwhile, the emissivity at $11 \mu \mathrm{m}$ increases with increasing particle size (e.g. Salisbury \& Wald, 1992; Wald, Kaufman, Tanre, \& Gao, 1998; Wald \& Salisbury, 1995; Wenrich \& Christensen, 1996). Therefore, the BTR(11/8.6) shows a higher value over the desert surface than dust-laden condition because the particle size of dust is smaller than that of the particles on the desert surface. 
a

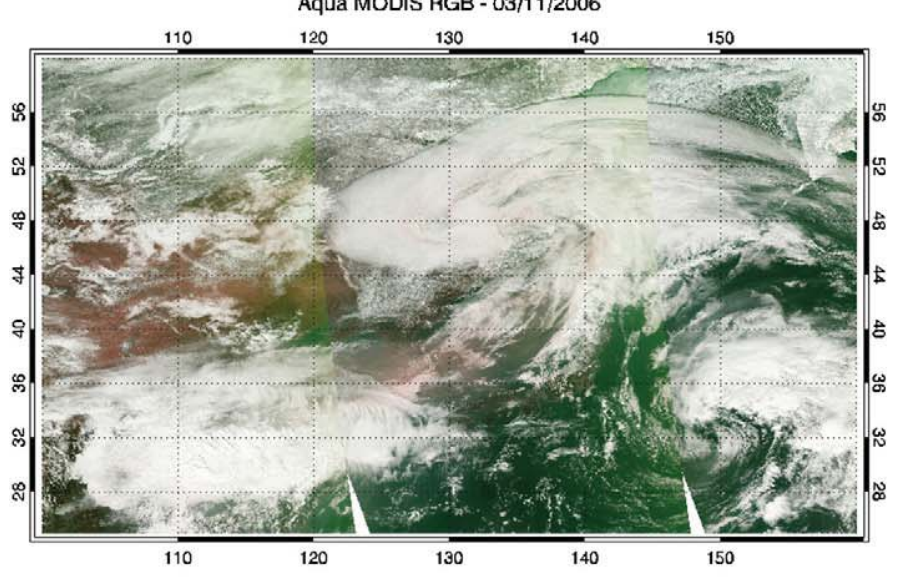

C

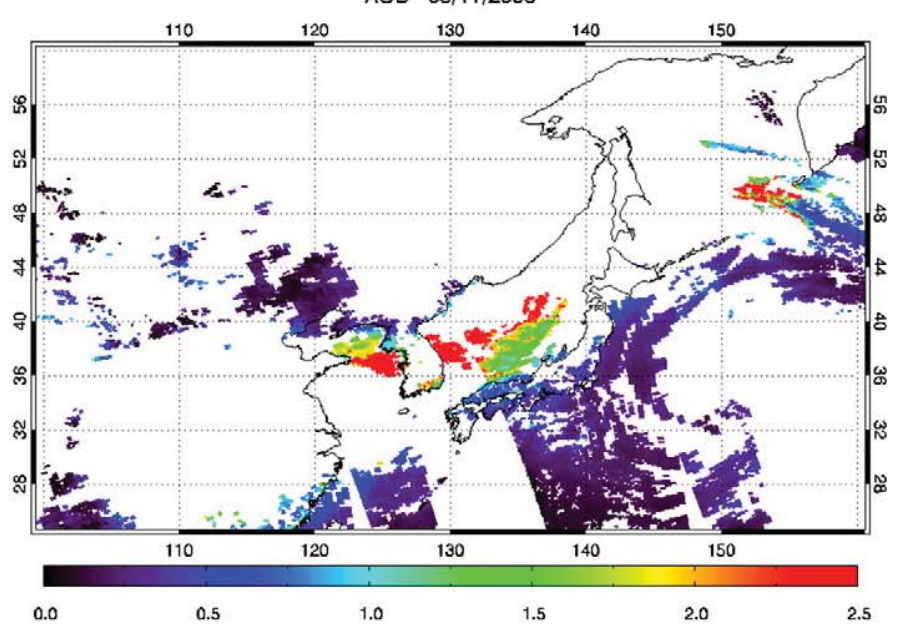

e

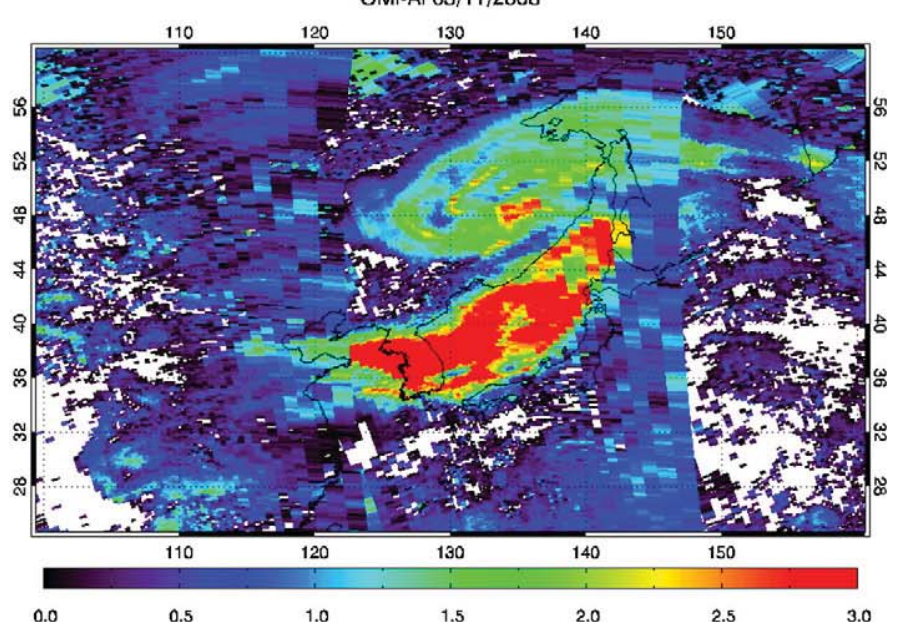

b

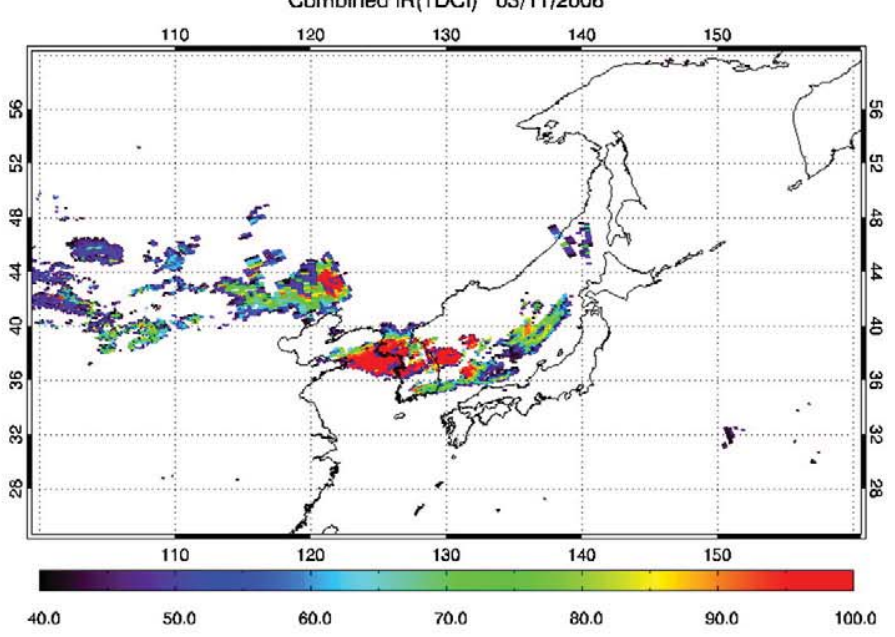

d

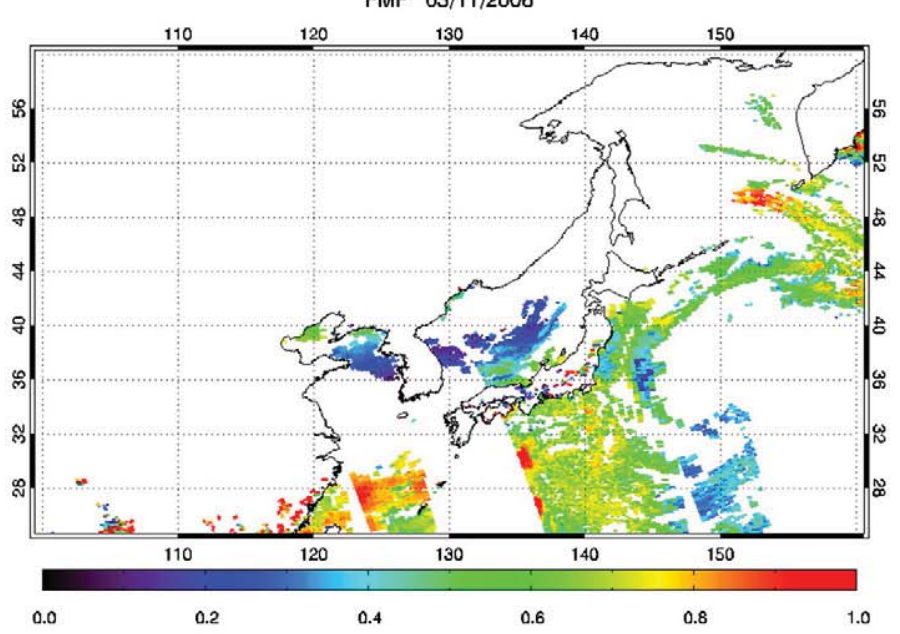

f

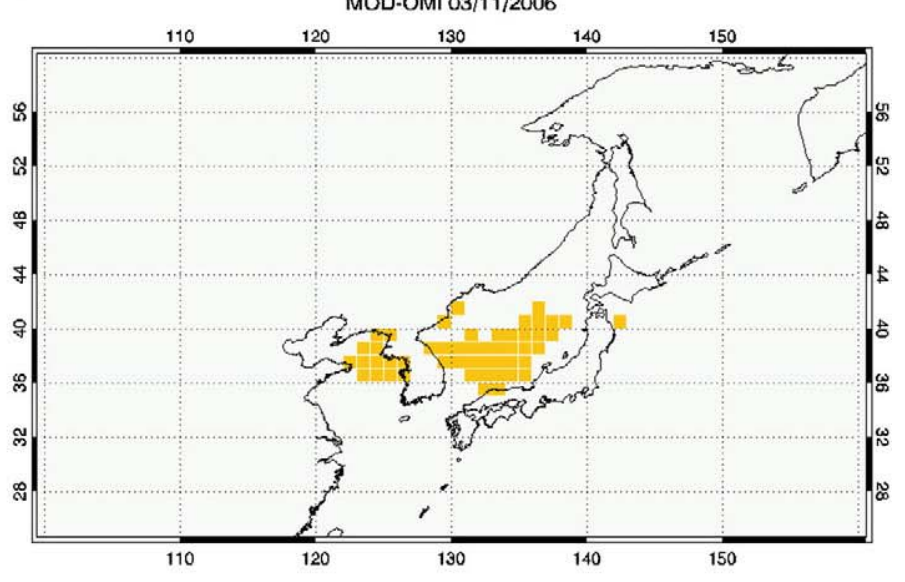

Fig. 7. (a) MODIS RGB image, (b) dust from IR algorithm, (c) MODIS AOD, (d) FMF, (e) OMI AI, and (f) dust detection (yellow color) from MODIS-OMI algorithm (MOA) on March 11, 2006.

The estimation of C-BTR(11/8.6) follows the same process as the calculation of C-BTR(11/12) except for the wavelength pair of 11 and $8.6 \mu \mathrm{m}$. BTR(11/8.6) can be used even over the desert surface. Gangale,
Prata, and Clarisse (2010) showed that the BTs between 8.6 and $11 \mu \mathrm{m}$ have an inclination in dust conditions, while the values become almost constant in clear conditions. However, the absorption bands of the sulfur 
a

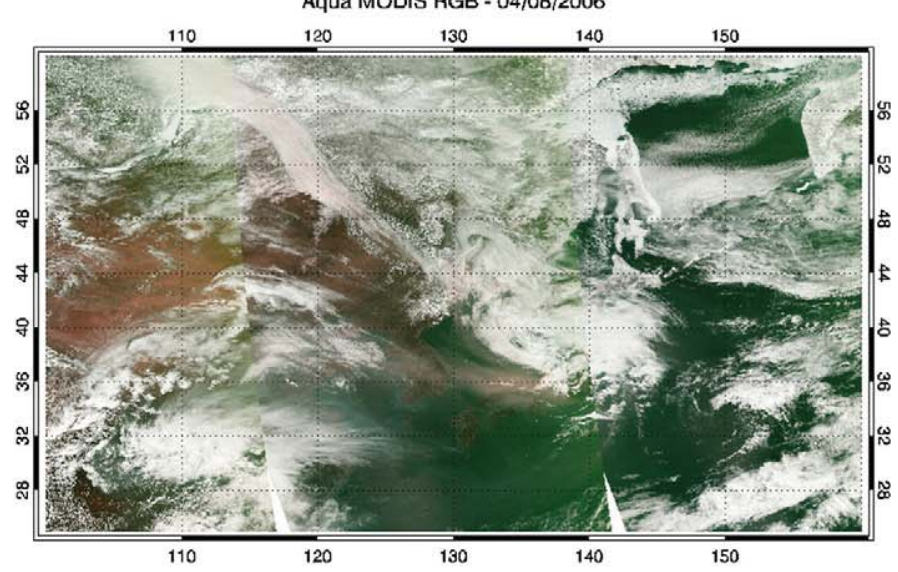

C

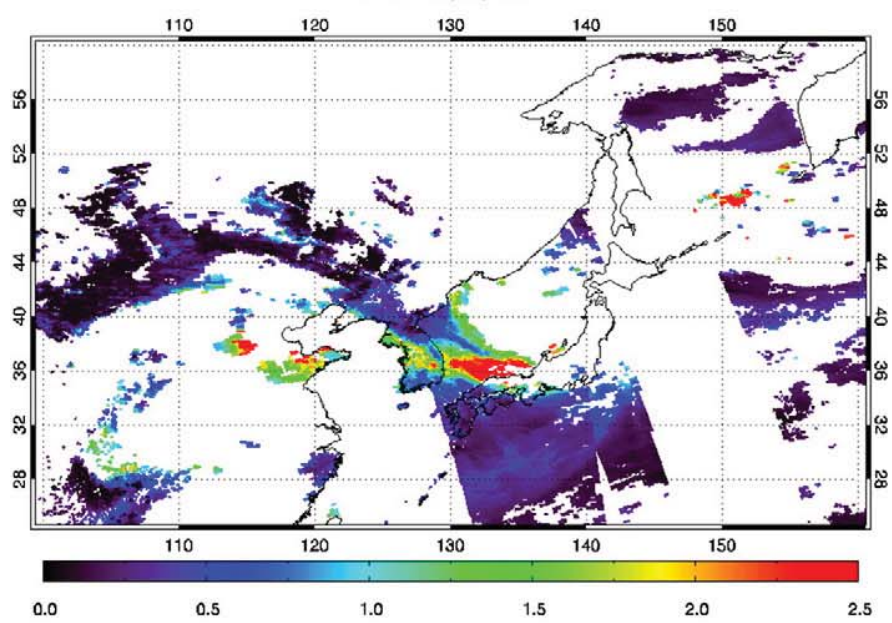

e

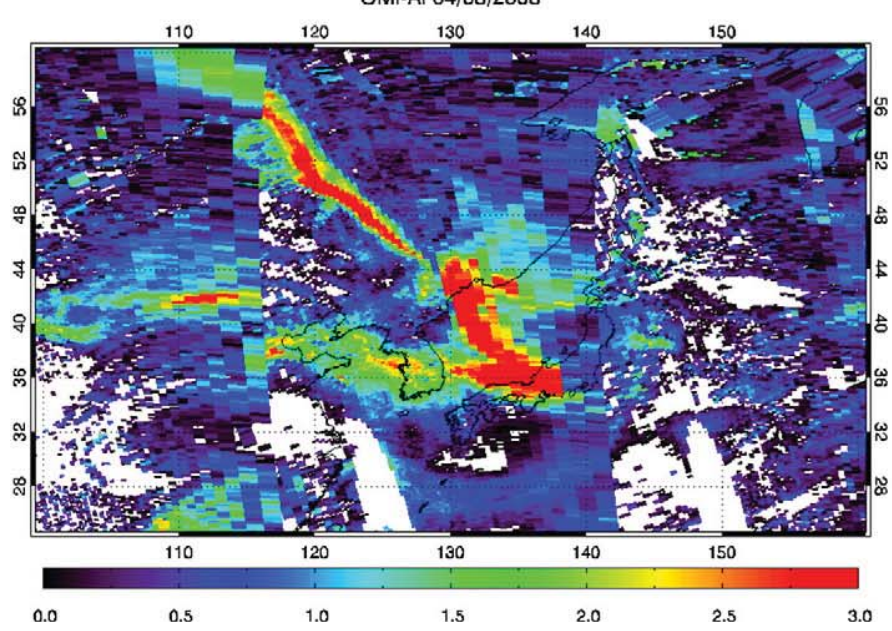

b

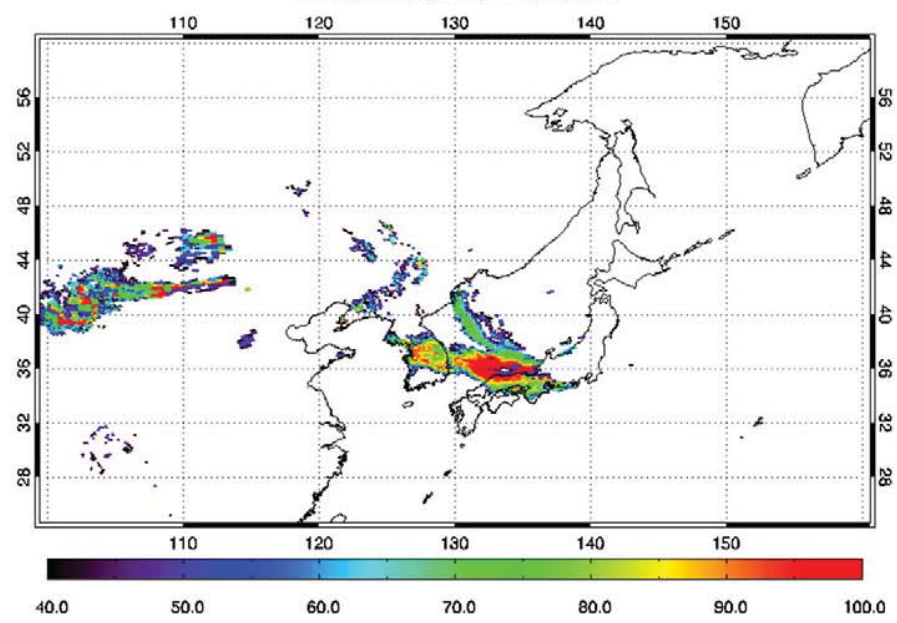

d

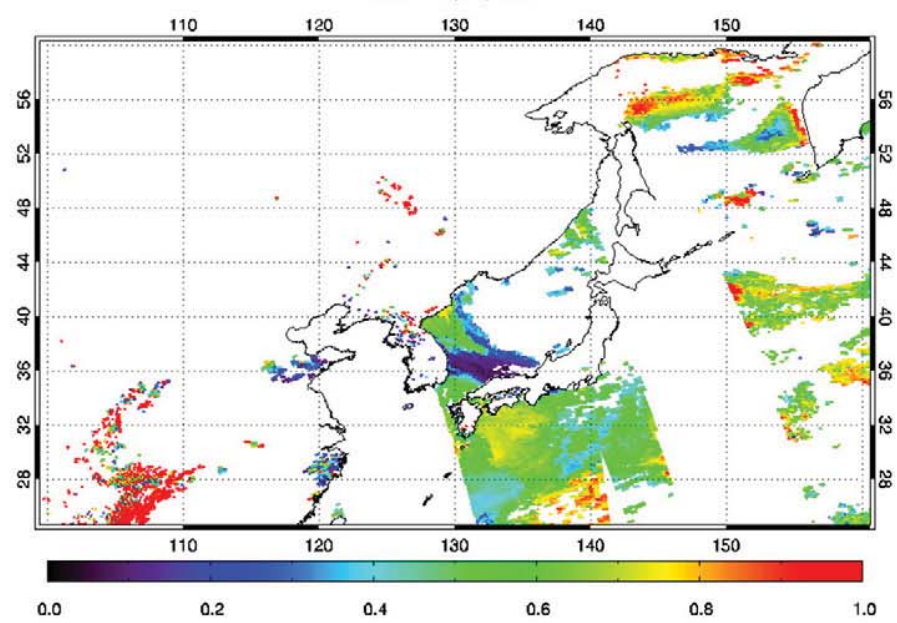

f

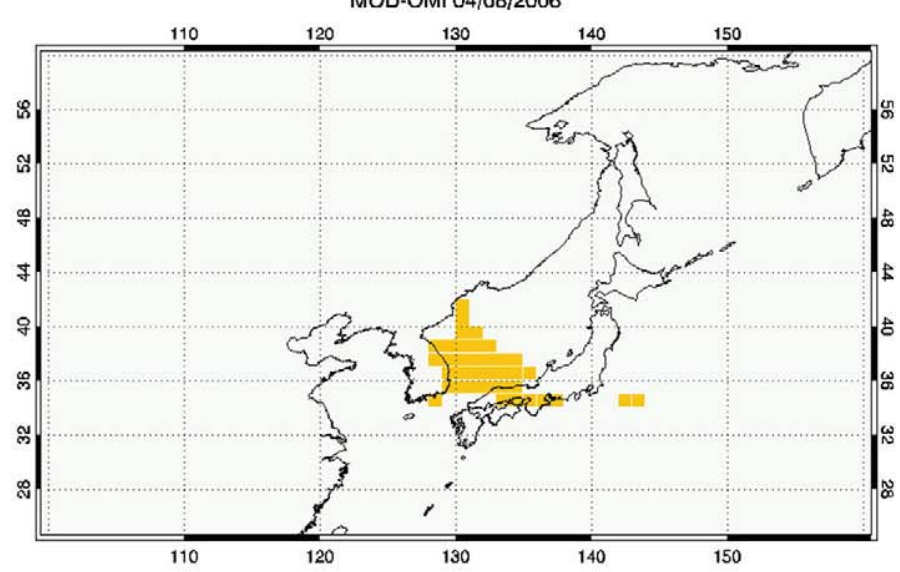

Fig. 8. Same as in Fig. 7 except for the case on April 8, 2006.

dioxide and water vapor in the MODIS $8.6 \mu \mathrm{m}$ band have an effect on the BTR(11/8.6). Although the absorption in $8.6 \mu \mathrm{m}$ is weak, even small errors can cause an error in dust detection because of the low BTR sensitivity to dust. Furthermore, cloud also affects the dust detection. Gangale et al. (2010) showed that the BT variation between 11 and $8.6 \mu \mathrm{m}$ in dust conditions was similar to that in cloud conditions. 
Therefore, accurate cloud detection techniques are necessary to separate dust and cloud signal for this method.

\subsection{4. $D^{*}$-parameter test}

Thin cirrus clouds are occasionally misclassified as dust plumes when using a single BTD test. For this reason, Hansell et al. (2007) investigated a $\mathrm{D}^{*}$-Parameter $\left(\mathrm{D}^{*}\right)$ test to distinguish cirrus clouds from dust signals. The $\mathrm{D}^{*}$-parameter is estimated by the following expression

$\mathrm{D} *=\exp [(\mathrm{BTD}(11-12)-a) /(\mathrm{BTD}(8.6-11)-b)]$

where $a$ and $b$ are offset values for $\operatorname{BTD}(11-12)$ and $\operatorname{BTD}(8.6-11)$, respectively. From Hansell et al. (2007), the offset values used were -0.5 and 15.0 for $a$ and $b$, respectively. Extensive model calculations showed that the $\mathrm{D}^{*}$-parameter increases for dust, while it decreases for cirrus with increasing optical depth. Based on this result, the $\mathrm{D}^{*}$ value can be used to classify cirrus and dust without cloud masking. The previous studies (Baddock et al., 2009; Hansell et al., 2007) proposed a $D^{*}$ threshold value of 1.0 to detect dust.

\subsection{Cloud masking}

Cloud is one of the main error sources for dust detection. Theoretically, the BTD(11-12) values of cloud show weakly positive values and the values increase with the cloud optical depth (Roskovensky \& Liou, 2005). However, high-level clouds and high latitudinal clouds are frequently observed with negative or near zero values of BTD(11-12) (Iino, Kinoshita, Tupper, \& Yano, 2004). In addition, the inclination of the BT values between 8.6 and $11 \mu \mathrm{m}$ observed for clouds is similar to that for dust conditions. Therefore, cloud needs to be masked out before the DCI calculation for better accuracy. In this study, three tests are applied for cloud detection. First, the conventional BT(11) test is performed to detect clouds. Second, the correlation of the BTs determined by the determination coefficient $\left(R^{2}\right)$ between 7.3 and $11 \mu \mathrm{m}$ is used [referred to as the $\mathrm{R}^{2}(7.3-11)$ test hereafter]. These two tests are performed in a $10 \mathrm{~km} \times 10 \mathrm{~km}$ grid box to detect spatially larger clouds. Third, the dynamic range of the BT(11) within the $10 \mathrm{~km} \times 10 \mathrm{~km}$ grid box is used additionally to detect sub-grid clouds [BT(11) variation test hereafter] from $1 \mathrm{~km} \times 1 \mathrm{~km}$ observation data. The flowchart of the cloud masking technique is presented in Fig. 3, and an example of the a

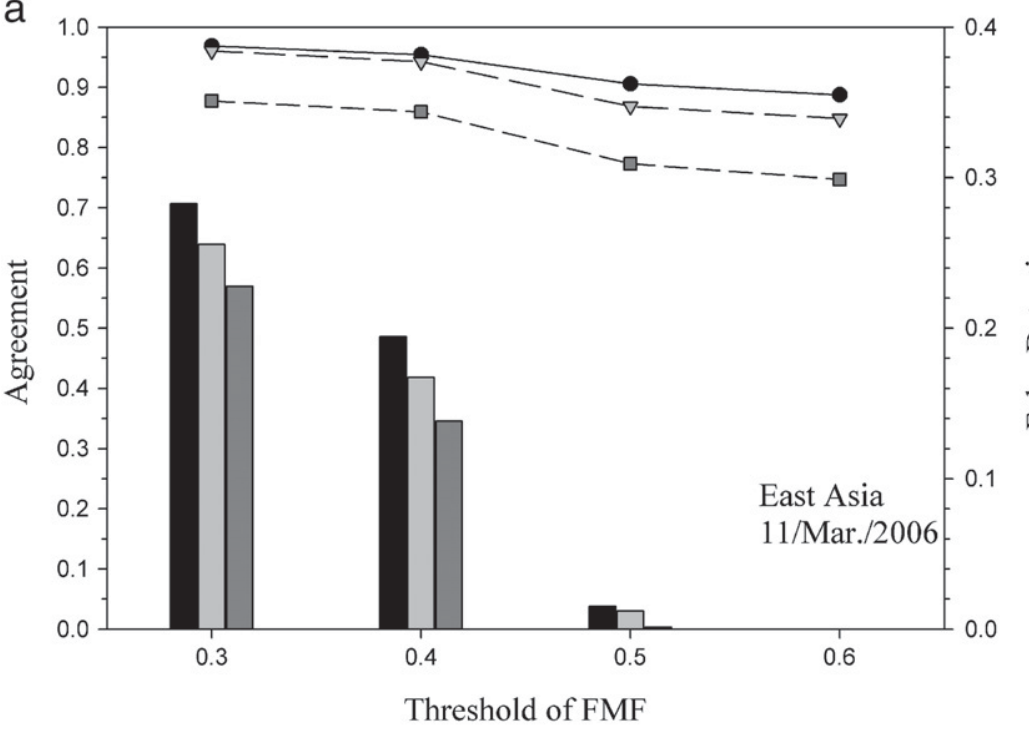

b

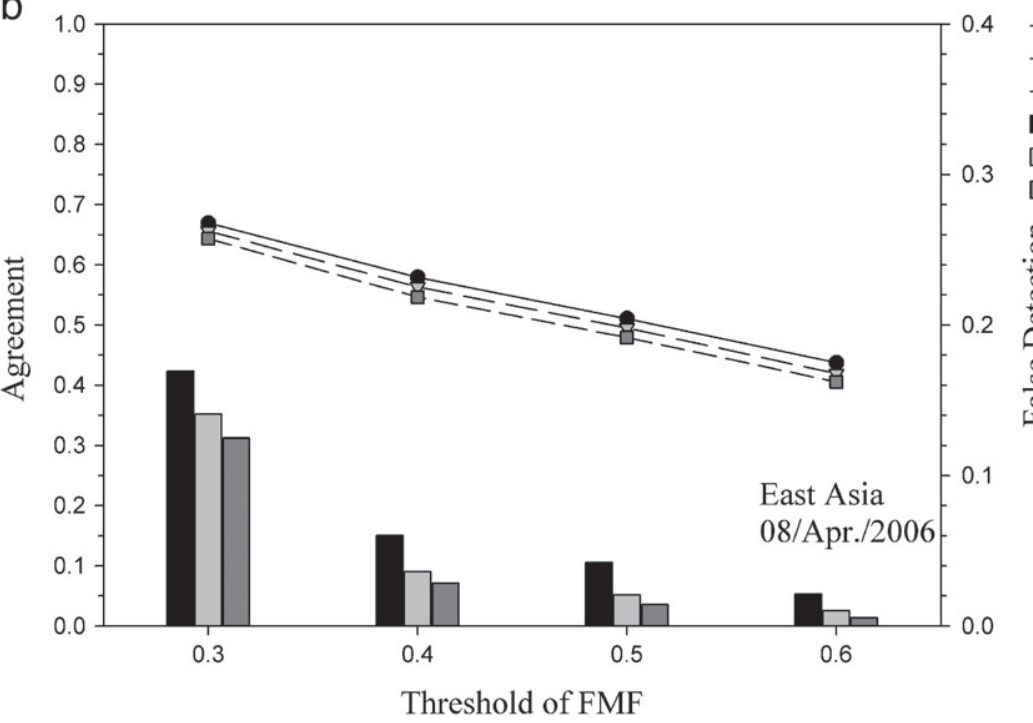

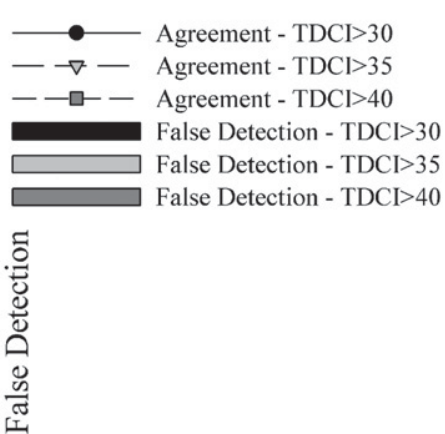

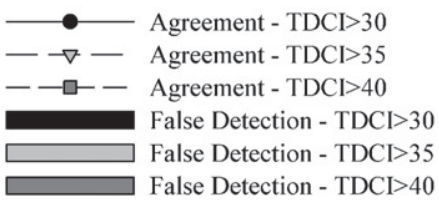

흠

Fig. 9. The agreement and the false detection of dust between IR algorithm and MODIS FMF for the case of (a) March 11, and (b) April 8, 2006. 
cloud masking result is shown in Fig. 4. In Fig. 4(a), the current cloud masking method defines the cloud and non-cloud regions, which are indicated by blue and white coloring, respectively. In comparison with the RGB image in Fig. 4(b), the cloud regions are well defined by the current cloud masking method. Although more accurate cloud detection can be achieved using the visible band, only the IR bands are used for nighttime application.

\subsubsection{BT(11) test}

BT(11) is a simple way to obtain skin temperatures of surface and optically thick materials. For thick clouds, BT(11) shows lower value compared to those of the terrestrial surface. For this reason, BT(11) is a powerful tool to detect optically thick clouds or clouds at highaltitudes. In this study, the maximum value of BT(11) was calculated for the past 30 days $\left(T_{\max }\right)$ as a reference value. Then, the threshold of cloud temperature $\left(T_{c l d}\right)$ is calculated by multiplying $T_{\max }$ by a coefficient $\alpha$ of 0.95 based on the upper threshold of BT(11) (=273 K) from Ackerman et al. (1998) and the surface temperature (288.2 K) from the
US standard atmosphere (1976). The low-level clouds (e.g. stratus and stratocumulus), however, cannot be detected using this method due to the difficulty in distinguishing signals of low clouds from that of surface, as well as the weak contrast of BT(11) between terrestrial surface and low-level cloud.

\subsection{2. $R^{2}(7.3-11)$ test}

The weighting function peak of the MODIS band $28(7.3 \mu \mathrm{m})$ is located at around 500 to $600 \mathrm{hPa}$ (Tang \& Li, 2008). In contrast, the peak of the MODIS band $31(11 \mu \mathrm{m})$ is located at the surface. Therefore, BT(7.3) and BT(11) change simultaneously over high-level clouds, while only BT(11) changes over dust-laden pixels due to the insensitivity of dust at $7.3 \mu \mathrm{m}$. For these reasons, the $\mathrm{R}^{2}$ value between $\mathrm{BT}(7.3)$ and $\mathrm{BT}(11)$ becomes higher for cloudy condition than that for the clear condition.

Fig. 5 shows the count distributions of calculated $\mathrm{R}^{2}$ over East Asia for the period from January to June, 2006. The $\mathrm{R}^{2}$ is calculated for each $10 \times 10$ pixels, with data in $1 \mathrm{~km} \times 1 \mathrm{~km}$ resolution. This result was compared with the MODIS standard products introduced by Martins

a

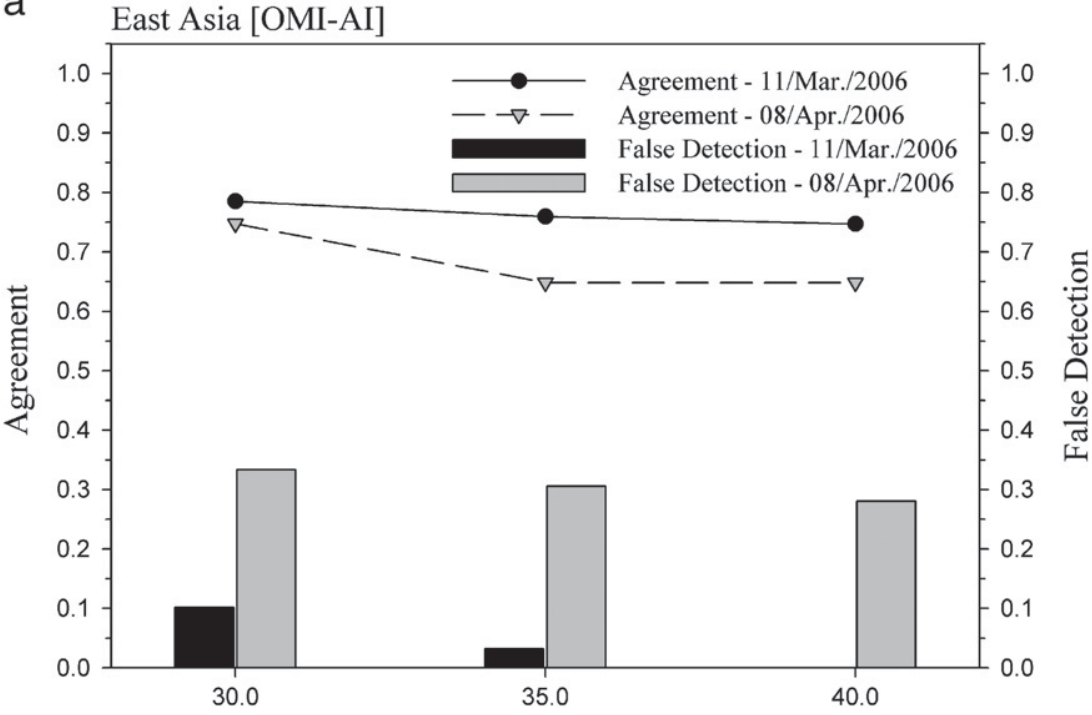

Threshold of TDCI

b

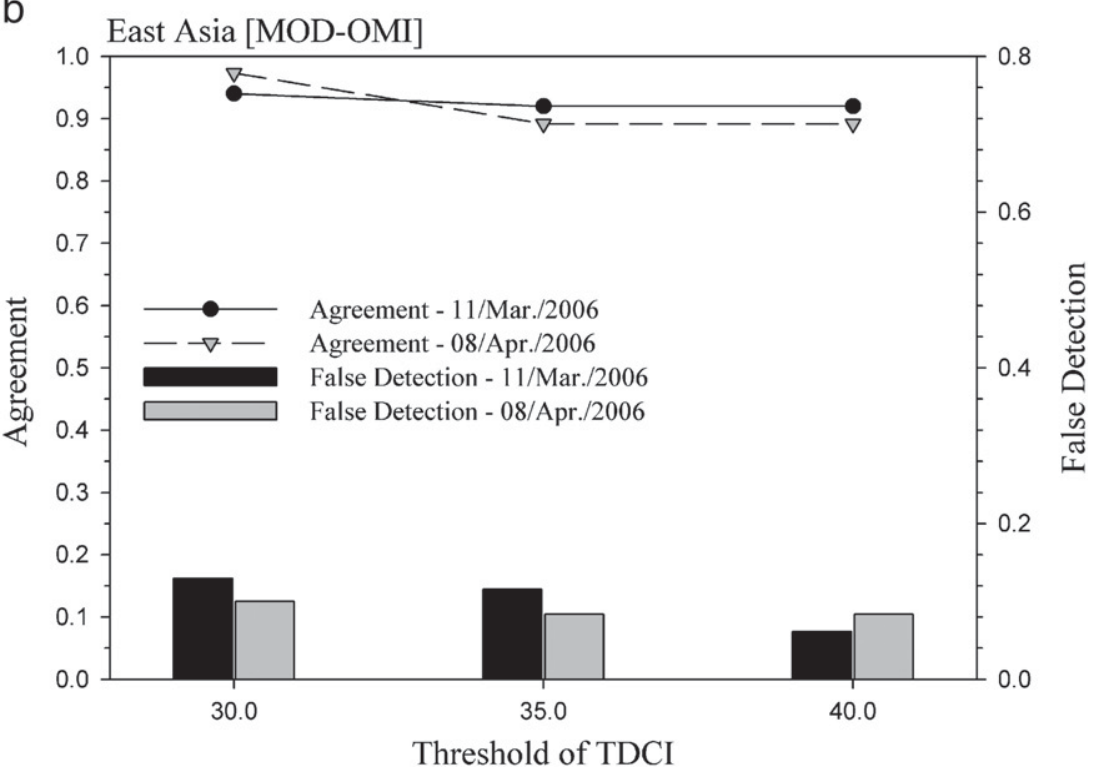

Fig. 10. (a) The agreement and the false detection of dust between the IR algorithm and the OMI AI and (b) MOA for the case of March 11, and April 8, 2006. 
et al. (2002) and Remer et al. (2005). To minimize the false detection of clouds, only $4.2 \%$ of the clear pixels are allowed to be detected as cloudy, so that $47.7 \%$ of the cloud pixels can be detected by the $\mathrm{R}^{2}$ threshold of 0.9 for the time period.

\subsubsection{BT(11) variation test}

The BT(11) in cloudy pixels is lower than that of clear pixels. While the decrease in the mean BT(11) in the $10 \mathrm{~km} \times 10 \mathrm{~km}$ resolution is hardly visible for small-scale clouds, the BT(11) in the $1 \mathrm{~km} \times 1 \mathrm{~km}$ resolution can detect better signals from small-scale clouds than the $10 \mathrm{~km}$ pixel resolution. The difference between the maximum and minimum values of the $\mathrm{BT}(11)$ observed in the $1 \mathrm{~km}$ pixel resolution in the target grid ( $10 \times 10$ pixels) is expected to show a higher value when covered by small-scale clouds. To minimize errors caused by locality, the variation is defined by the difference between the mean BT(11) of the upper $20 \%$ and that of lower $20 \%\left(\Delta \mathrm{T}_{\text {sub }}\right)$. Fig. 6 shows the count distribution of the $\Delta \mathrm{T}_{\text {sub }}$ over East Asia. When allowing for $0.7 \%$ false detection, the $\Delta \mathrm{T}_{\text {sub }}$ threshold of $5.0 \mathrm{~K}$ is determined to have a $51.9 \%$ of cloud detection rate. The rest of the $48.1 \%$ is mainly due to large-scale clouds, which can be detected effectively by the previous two tests.

\section{Detection results and validation}

To evaluate the developed algorithm (IR algorithm hereafter), detected results are compared with the RGB images, the AOD and fine mode fraction (FMF) from MODIS, the UV aerosol index (AI) from the Ozone Monitoring Instrument (OMI), and dust classification from the so-called MODIS-OMI algorithm (MOA hereafter) (Jeong \& Li, 2005; Kim et al., 2007; Lee, Kim, Lee, \& Takemura, 2007). The FMF is defined as a ratio of the fine-mode AOD to the total AOD, so this value can be used to identify dominant aerosol size, i.e. coarse or fine mode. Because dust is the coarse-mode dominant aerosol, the results of the IR algorithm are compared with the FMF as a reference. The $\mathrm{AI}$ is an index to contrast the wavelength dependence of the backscattered UV radiation between the aerosol-concerned atmosphere and pure molecular atmosphere (Herman et al., 1997). Therefore, the AI shows absorption characteristics of aerosols in the UV wavelength range. The MOA classifies dust as optically thick, UV-absorbing coarse-mode particles by using

Table 1

The agreement of dust between the IR algorithm and FMF.

\begin{tabular}{|c|c|c|c|c|}
\hline \multirow[t]{2}{*}{ Agreement (false detection) } & \multicolumn{4}{|c|}{$\mathrm{FMF}<0.4$} \\
\hline & $\mathrm{AOD}>0.4$ & $\mathrm{AOD}>0.6$ & $\mathrm{AOD}>0.8$ & $\mathrm{AOD}>1.0$ \\
\hline $\mathrm{TDCI}>30.0$ & $\begin{array}{l}0.207 \\
(0.513)\end{array}$ & $\begin{array}{l}0.424 \\
(0.499)\end{array}$ & $\begin{array}{l}0.651 \\
(0.490)\end{array}$ & $\begin{array}{l}0.814 \\
(0.418)\end{array}$ \\
\hline TDCI $>35.0$ & $\begin{array}{l}0.175 \\
(0.476)\end{array}$ & $\begin{array}{l}0.366 \\
(0.471)\end{array}$ & $\begin{array}{l}0.616 \\
(0.460)\end{array}$ & $\begin{array}{l}0.799 \\
(0.396)\end{array}$ \\
\hline $\mathrm{TDCI}>40.0$ & $\begin{array}{l}0.146 \\
(0.444)\end{array}$ & $\begin{array}{l}0.313 \\
(0.446)\end{array}$ & $\begin{array}{l}0.562 \\
(0.433)\end{array}$ & $\begin{array}{l}0.764 \\
(0.379)\end{array}$ \\
\hline \multirow[t]{2}{*}{ Agreement (false detection) } & \multicolumn{4}{|c|}{$\mathrm{FMF}<0.5$} \\
\hline & $\mathrm{AOD}>0.4$ & $\mathrm{AOD}>0.6$ & $\mathrm{AOD}>0.8$ & $\mathrm{AOD}>1.0$ \\
\hline $\mathrm{TDCI}>30.0$ & $\begin{array}{l}0.194 \\
(0.263)\end{array}$ & $\begin{array}{l}0.388 \\
(0.240)\end{array}$ & $\begin{array}{l}0.620 \\
(0.189)\end{array}$ & $\begin{array}{l}0.779 \\
(0.115)\end{array}$ \\
\hline $\mathrm{TDCI}>35.0$ & $\begin{array}{l}0.161 \\
(0.219)\end{array}$ & $\begin{array}{l}0.331 \\
(0.207)\end{array}$ & $\begin{array}{l}0.572 \\
(0.163)\end{array}$ & $\begin{array}{l}0.755 \\
(0.095)\end{array}$ \\
\hline $\mathrm{TDCI}>40.0$ & $\begin{array}{l}0.132 \\
(0.190)\end{array}$ & $\begin{array}{l}0.277 \\
(0.189)\end{array}$ & $\begin{array}{l}0.504 \\
(0.151)\end{array}$ & $\begin{array}{l}0.711 \\
(0.082)\end{array}$ \\
\hline \multirow[t]{2}{*}{ Agreement (false detection) } & \multicolumn{4}{|c|}{$\mathrm{FMF}<0.6$} \\
\hline & $\mathrm{AOD}>0.4$ & $\mathrm{AOD}>0.6$ & $\mathrm{AOD}>0.8$ & $\mathrm{AOD}>1.0$ \\
\hline $\mathrm{TDCI}>30.0$ & $\begin{array}{l}0.162 \\
(0.146)\end{array}$ & $\begin{array}{l}0.345 \\
(0.131)\end{array}$ & $\begin{array}{l}0.557 \\
(0.074)\end{array}$ & $\begin{array}{l}0.724 \\
(0.032)\end{array}$ \\
\hline $\mathrm{TDCI}>35.0$ & $\begin{array}{l}0.133 \\
(0.105)\end{array}$ & $\begin{array}{l}0.293 \\
(0.098)\end{array}$ & $\begin{array}{l}0.510 \\
(0.052)\end{array}$ & $\begin{array}{l}0.689 \\
(0.027)\end{array}$ \\
\hline $\mathrm{TDCI}>40.0$ & $\begin{array}{l}0.108 \\
(0.078)\end{array}$ & $\begin{array}{l}0.245 \\
(0.078)\end{array}$ & $\begin{array}{l}0.448 \\
(0.042)\end{array}$ & $\begin{array}{l}0.643 \\
(0.022)\end{array}$ \\
\hline
\end{tabular}

the Angstrom Exponent ( $\mathrm{AE}$ ) from MODIS for the aerosol size parameter, and the AI from OMI for the aerosol absorptivity in UV, simultaneously. Due to the different geometry of the pixels between MODIS and OMI, the results of MOA are gridded data resolution of $1.0^{\circ} \times 1.0^{\circ}$. Similarly, the data of AI from OMI is also gridded at a resolution of $1.0^{\circ} \times 1.0^{\circ}$ for comparison purposes. The AI from OMI uses the thresholds for $\mathrm{AOD}>0.4$ and $\mathrm{AI}>0.7$. The MOA uses the thresholds for $\mathrm{AOD}>0.4, \mathrm{AE}<0.7$ and $\mathrm{AI}>0.7$ (Kim et al., 2007). Note that AOD and FMF represent the values at $550 \mathrm{~nm}$ unless specified in the subscript.

\subsection{Case study}

Strong Asian dust case on March 11 and April 8, 2006 is shown in Figs. 7 and 8, respectively. On March 11, 2006, thick dust layer, mixed with clouds, is observed over the Yellow Sea through the eastern part of the Korean Peninsula from the MODIS RGB image as shown in Fig. 7(a). The new IR algorithm successfully detects the thick dust layer with TDCI values of almost 100, and it also detects a relatively thin dust layer over the northern part of Japan with values at around 70 to 80, as shown in Fig. 7(b). Fig. 7(c) and (d) shows the thick dust layer with AODs higher than 1.5 and FMF lower than 0.5 , respectively, which indicates coarse-mode dominance. Fig. 7(e) shows AI from OMI with values higher than 2.5 , representing strong UV absorption, over the dust layer located from the Yellow Sea to the northern part of Japan. As inferred from the aerosol type classification from the MOA [Fig. 7(f)], dust aerosols are detected over the dust-laden area as inferred from the RGB image and the retrieval results from MODIS. The dust layer over the Korean Peninsula is not detected by the MODIS shortwave algorithms, while the AI from OMI shows significant sensitivity to the dust layer over the clouds. The current IR algorithm shows the continuous structure of the dust layer detected over the Korean Peninsula compared to the operational MODIS shortwave algorithm over land. In addition, the IR algorithm shows sensitivity to the weak dust layer over Northeastern China with the TDCI higher than 70.0, where the AOD was about 0.3.

Fig. 8 shows another dust outbreak on April 8, 2006. A thick dust layer can be observed over the Korean Peninsula extending to the western part of Japan in the RGB image as shown in Fig. 8(a). The MODIS shortwave retrieval shows strong coarse-mode dominant aerosols, which have the AOD ranging from 1.0 to 3.0 [see Fig. 8(c)] and the FMF ranging from 0.1 to 0.6 [see Fig. $8(\mathrm{~d})$ ], over the dust-laden area as inferred from the RGB image. Fig. 8(e) shows the AI values higher than 1.5 over the investigated region. In particular, the AI shows the core of the dust plume observed from the Korean Peninsula to Japan with the AI values higher than 2.5. The result of the MOA also classifies the dust type aerosol over this area as shown in Fig. 8(f). The result of the current IR algorithm in Fig. 8(b) also shows high confidence of the dust (TDCI $>70.0$ ) over both land and ocean. In particular, the TDCI reaches almost 100 over the dust layer with a very high AOD value (AOD $>2.0$ ) and low FMF value (FMF $<0.2)$. In addition, the developed algorithm detects dust with a TDCI higher than 60 over the Gobi Desert, where OMI AI shows enhanced values, but the MODIS AOD indicates thin aerosol layer.

To evaluate the statistical results of the developed algorithm, the agreement and false detection are calculated by using following equations,

Agreement $=\mathrm{Y}_{\mathrm{IR} \& \mathrm{SW}} / \mathrm{Y}_{\mathrm{SW}}$

False detection $=1-\mathrm{Y}_{\mathrm{IR} \& \mathrm{SW}} / \mathrm{Y}_{\mathrm{IR}}$

where $Y_{\text {IR\&SW }}$ denotes the number of dust pixels defined by both the IR algorithm and the shortwave (SW) algorithms, simultaneously (low FMF, high $\mathrm{AI}$, and dust result from MOA). $\mathrm{Y}_{\mathrm{IR}}$ and $\mathrm{Y}_{\mathrm{SW}}$ denote the number of dust pixels detected by the IR algorithm and the SW algorithms, respectively. For statistical calculations, the pixels with the AOD value 


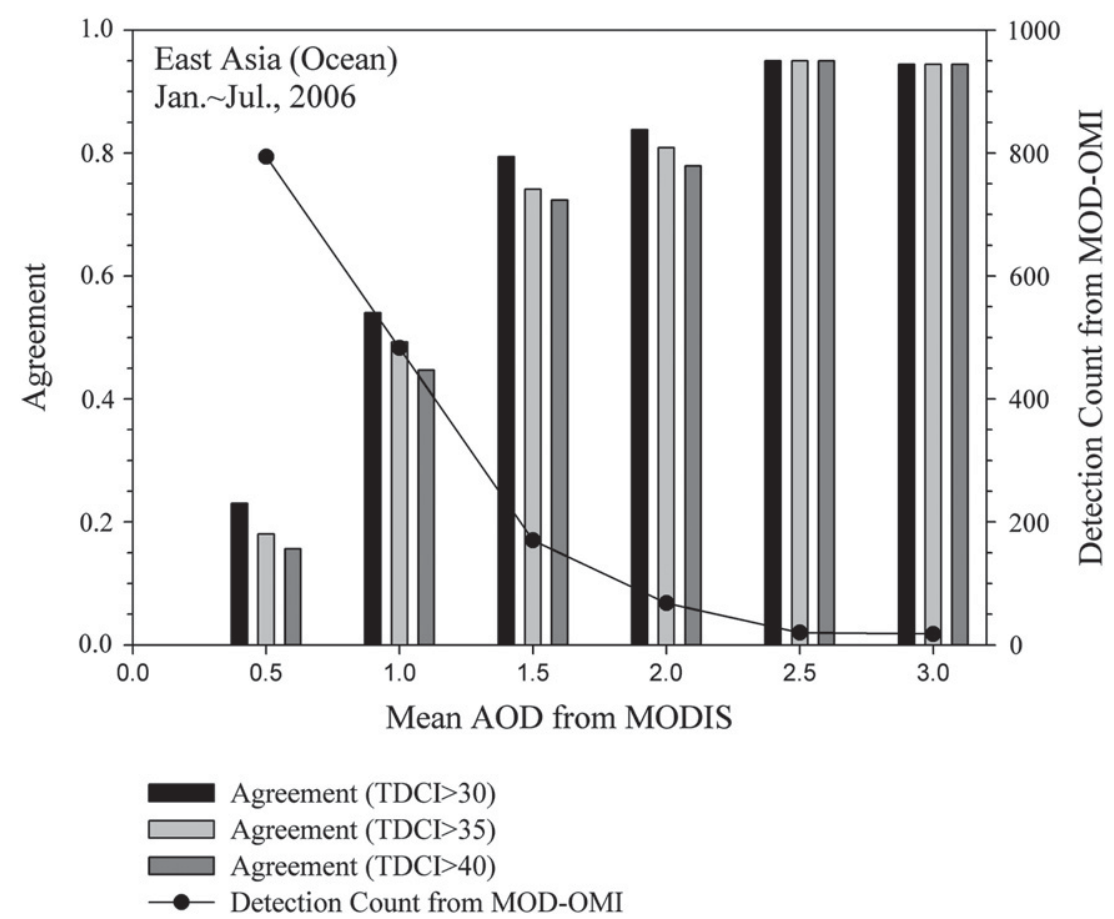

Fig. 11. The agreements of dust between the IR algorithm and MOA as a function of AOD for the period from January to June, 2006

higher than 0.4 are used for intercomparison to ensure the retrieval accuracy of the SW algorithms. By doing so, the coarse-mode aerosol determined by a low FMF from MODIS can be assumed to be dust, because the AOD for sea salt is very low in general. Due to the inaccuracy of the size information retrieval from MODIS over land (Levy, Remer, Tanre, Mattoo, \& Kaufman, 2009), the FMF and MOA are used only over ocean.

Fig. 9(a) and (b) shows the agreement and false detection of dust results between the IR algorithm and the MODIS FMF on March 11 and April 8, 2006, respectively. Because the FMF can be influenced by cloud fraction (Zhang, Reid, \& Holben, 2005), the results are compared only with the data with a cloud fraction lower than 0.1 . The agreement between the dust inferred from the FMF and the IR algorithm ranges from 0.747 (FMF $<0.6$ and TDCI $>40.0$ ) to $0.969(\mathrm{FMF}<0.3$ and $\mathrm{TDCI}>30.0)$, and from 0.405 (FMF $<0.6$ and $\mathrm{TDCI}>40.0$ ) to 0.669 (FMF $<0.3$ and TDCI > 30.0) for the case on March 11 and April 8, respectively. Furthermore, the false detection ranges from 0.000 to 0.283 , and from 0.005 to 0.169 for the case on March 11 and April 8, respectively. The agreement and the false detection decrease with increase in the FMF threshold.

Fig. 10 shows the comparison results of the IR algorithm with the OMI AI and the MOA. Prospero, Ginoux, Torres, Nicholson, and Gill (2002) suggested that the Total Ozone Mapping Spectrometer (TOMS) can be used to detect the dust region with the AI value higher than 0.7. For this reason, the AI higher than 0.7 from the OMI is used as a reference value, assuming similar performance between the TOMS and OMI. Similar to the FMF, the AE is also influenced by cloud contamination. Therefore, the gridded AE for the MOA is calculated by averaging the operational MODIS AE only for the pixel with a cloud fraction lower than 0.3. The agreement between the IR algorithm and the AI ranges from 0.648 to 0.745 , while the false detection ranges from 0.000 to

Table 2

The agreement of dust between the IR algorithm and MOA.

\begin{tabular}{llll}
\hline Agreement (false detection) & TDCI $>30.0$ & TDCI $>35.0$ & TDCI $>40.0$ \\
\hline East Asia-ocean & 0.452 & 0.405 & 0.376 \\
& $(0.464)$ & $(0.390)$ & $(0.322)$ \\
\hline
\end{tabular}

0.333 for the two cases. In comparison with dust-laden pixels identified by the MOA, high values in agreement are observed, ranging from 0.920 to 0.940 , and from 0.892 to 0.973 , while the false detection ranges from 0.061 to 0.130 and from 0.083 to 0.100 on March 11, 2006 and on April 8,2006 , respectively.

For the two selected dust cases, the agreement ranges from 0.65 to 0.98 , and the false detection is less than 0.34 in general, from the comparisons among the several different algorithms. For the case on April 8 , the agreement with the FMF is decreased down to 0.4 with the FMF threshold of 0.6 , as the observed AOD is lower than 0.5, due to weak signals over the area within $25^{\circ} \mathrm{N}-30^{\circ} \mathrm{N}$ and $130^{\circ} \mathrm{E}-140^{\circ} \mathrm{E}$, in which dust is not detected by the MOA. However, a thin aerosol plume was observed over this region in the RGB image, which was detected as a thin-layered polluted dust by FMF and AI by its higher spatial resolution compared to the MOA.

In addition, the agreement with the MOA is higher than the agreement with the FMF and the AI by $20 \%$, and the false detection with the MOA is lower than that with the FMF and the AI. This result indicates that the degeneration of statistical scores for the FMF and the AI arises primarily from the lack of aerosol information. As a result, the current IR algorithm correctly defines the dust pixels, and shows the transport of the dust plume for several dust cases over East Asia.

\subsection{Long-term validation}

For long-term evaluation, the results between the IR algorithm and the shortwave algorithms are compared for six months from January to June, 2006. Table 1 summarizes the agreement and the false detection as functions of the thresholds for TDCI, AOD, and FMF. The agreement increases significantly as the threshold of the AOD increases. For the cases with AOD $>1.0$, the agreement ranges from 0.643 (FMF $<0.6$ and $\mathrm{TDCI}>40.0$ ) to 0.814 (FMF $<0.4$ and TDCI $>30.0$ ). In contrast, the false detection decreases with an increase in the TDCI and FMF thresholds. From these results, it can be inferred that the IR algorithm detects severe dust events over ocean reasonably well. Fig. 11 shows the agreement between the IR algorithm and the MOA as a function of the AOD over ocean. Note that the AOD value in Fig. 11 means that the gridded AOD value is within the range of \pm 0.25 . The agreement 
a

Jan. Jun., 2006

East Asia

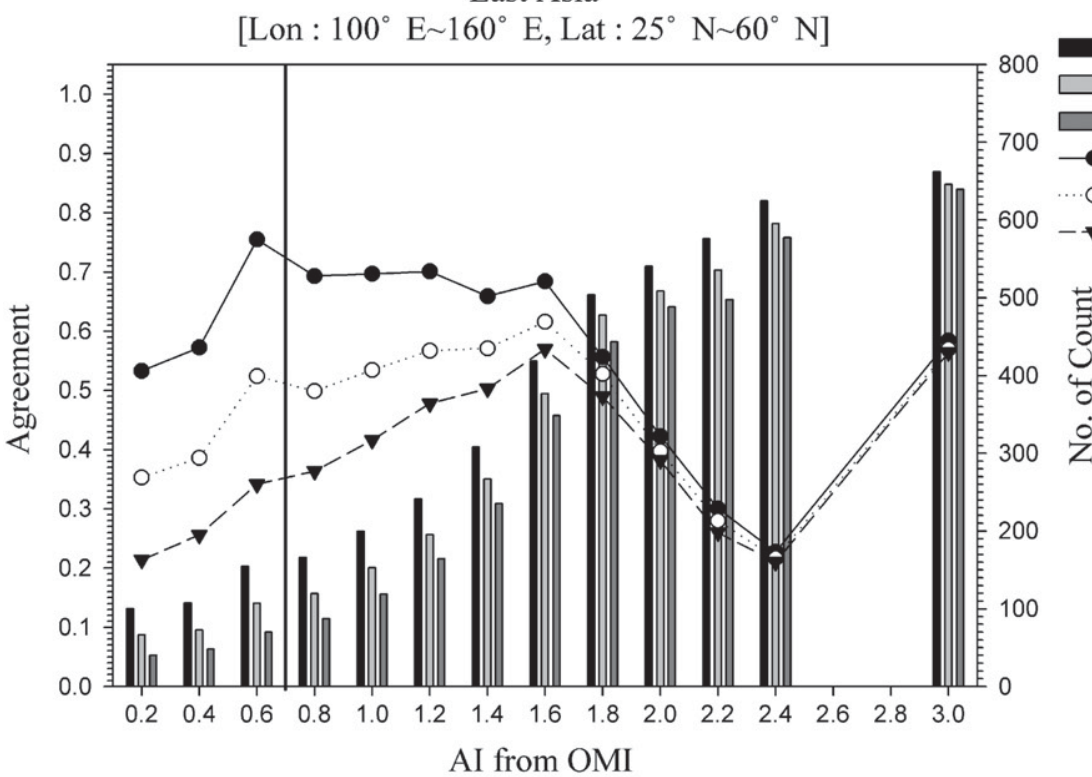

Agreement (TDCI $>30)$

Agreement $(\mathrm{TDCl}>35)$

Agreement (TDCI $>40)$

- Detection Count (TDCI $>30)$

.... Detection Count (TDCI $>35$ )

$-\boldsymbol{\nabla}-$ Detection Count (TDCI $>40$ )

b

Jan. $\sim$ Jun., 2006

Non-Polluted Land Region

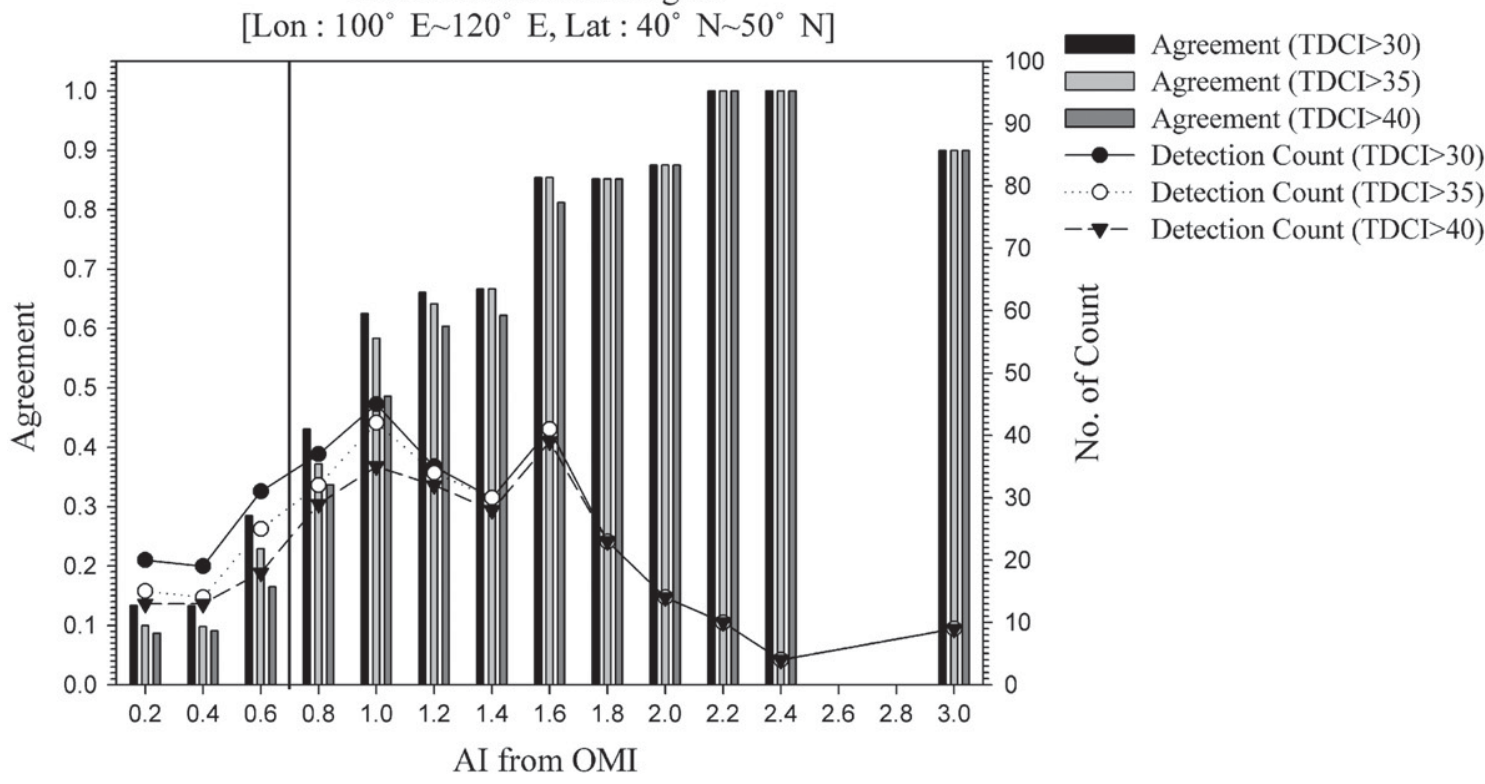

Fig. 12. The agreement between the IR algorithm and OMI AI in each bin (a) over East Asia, and (b) over non-polluted land area. Each AI interval is defined by AI between fore-median and aft-median of each AI value in the $\mathrm{x}$-axis.

generally increases with the AOD value due to the increased sensitivity of the IR measurements. The agreement between the IR algorithm and the MOA ranges from 0.724 to 0.950 for the MODIS AOD values higher

Table 3

The agreement of dust between the IR algorithm and $\mathrm{AI}(\mathrm{AI}>0.7)$.

\begin{tabular}{llll}
\hline Agreement (false detection) & TDCI $>30.0$ & TDCI $>35.0$ & TDCI $>40.0$ \\
\hline East Asia & 0.403 & 0.349 & 0.309 \\
& $(0.372)$ & $(0.308)$ & $(0.232)$ \\
Non-polluted land & 0.668 & 0.644 & 0.601 \\
& $(0.289)$ & $(0.244)$ & $(0.212)$ \\
\hline
\end{tabular}

than 1.25. For cases with low AOD values, however, the agreement ranges from 0.156 to 0.231 , and from 0.447 to 0.540 with AOD values lower than 0.75 and values in the range of 0.75 to 1.25 , respectively. Because of the low agreement in this case, the agreement between the IR algorithm and the MOA ranges from 0.376 to 0.452 in all of the pixels as listed in Table 2. Furthermore, the false detection ranges from 0.322 to 0.464 . The effective radius of aerosol from the MODIS has limitations due to the algorithm and sensor uncertainties for cases with low AOD values (Remer et al., 2002). Therefore, the large inconsistency between the IR algorithm and the shortwave algorithms for low AOD values is caused by not only the weak sensitivity of the IR measurements, but also by the uncertainties of the size parameters, the FMF and the AE, 
Table 4

The agreements of dust for the IR algorithm and negative BTD(11-12) referenced by (a) FMF, (b) AI and MOA.

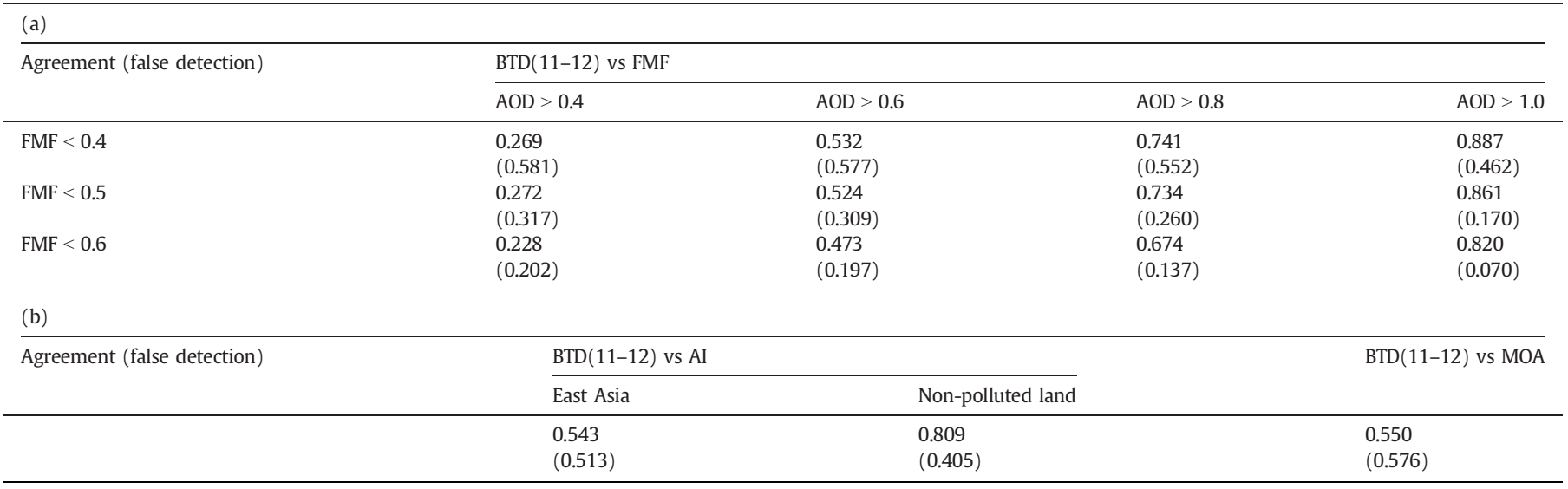

from MODIS due to the estimation error of the effective radius of aerosol.

Fig. 12 shows the agreement between dust pixels from the IR algorithm and the OMI AI in each bin. From the result, the agreement increases with an increase in the AI. For all of the OMI AI intervals, the agreement over the non-polluted land region is higher than that over East Asia by $20 \%$. The non-polluted region is defined as the area from $40^{\circ} \mathrm{N}$ to $50^{\circ} \mathrm{N}$ and from $100^{\circ} \mathrm{E}$ to $120^{\circ} \mathrm{E}$. As listed in Table 3, the agreement of the dust between the IR algorithm and the OMI AI ranges from 0.309 to 0.403 , and the false detection ranges from 0.232 to 0.372 over East Asia. Otherwise, the value ranges from 0.601 to 0.668 and from 0.212 to 0.289 for the agreement and the false detection, respectively, over the non-polluted land area. The difference in the agreement can be explained by the existence of fine-mode absorbing aerosols (e.g. black carbon), which also results in high AI values.

Table 4 shows the agreements compared with the FMF, AI, and dust from the MOA over ocean. Over ocean, the agreement of the BTD(11-12) method is higher than that of the current IR algorithm, but the false detection of the $\operatorname{BTD}(11-12)$ method is also higher than that of the IR algorithm. The agreement values ranged from 20 to $40 \%$, and the false detection values ranged from 20 to $60 \%$, of the BTD, which are larger than those of the IR algorithm. As a result, we conclude that the accuracy of dust detection is comparable between the two results over ocean. Over land (especially over the non-polluted land region), the agreement of the BTD with the AI shows 0.809, compared with from 0.604 to 0.668 with those of TDCI values. However, the false detection of the BTD method is 0.405 , which is larger than that of the IR algorithm by 40 to $100 \%$. This high false detection value from the BTD method implies that a large portion of the desert area is detected as a dust-laden area due to the limitation in resolving the surface properties.

Fig. 13 compares the dust detection between the IR algorithm and the AERONET observations at four AERONET sites, as summarized in Table 5. For the aerosol type classification from the AERONET, the dust-laden date from the AERONET is defined by $\mathrm{AE}<0.8$ with AOD $>0.4$ as suggested by Lee et al. (2007). For this comparison, the proportion of dust pixels from the IR algorithm is investigated by the ratio between the number of dust pixels and that of the total pixels

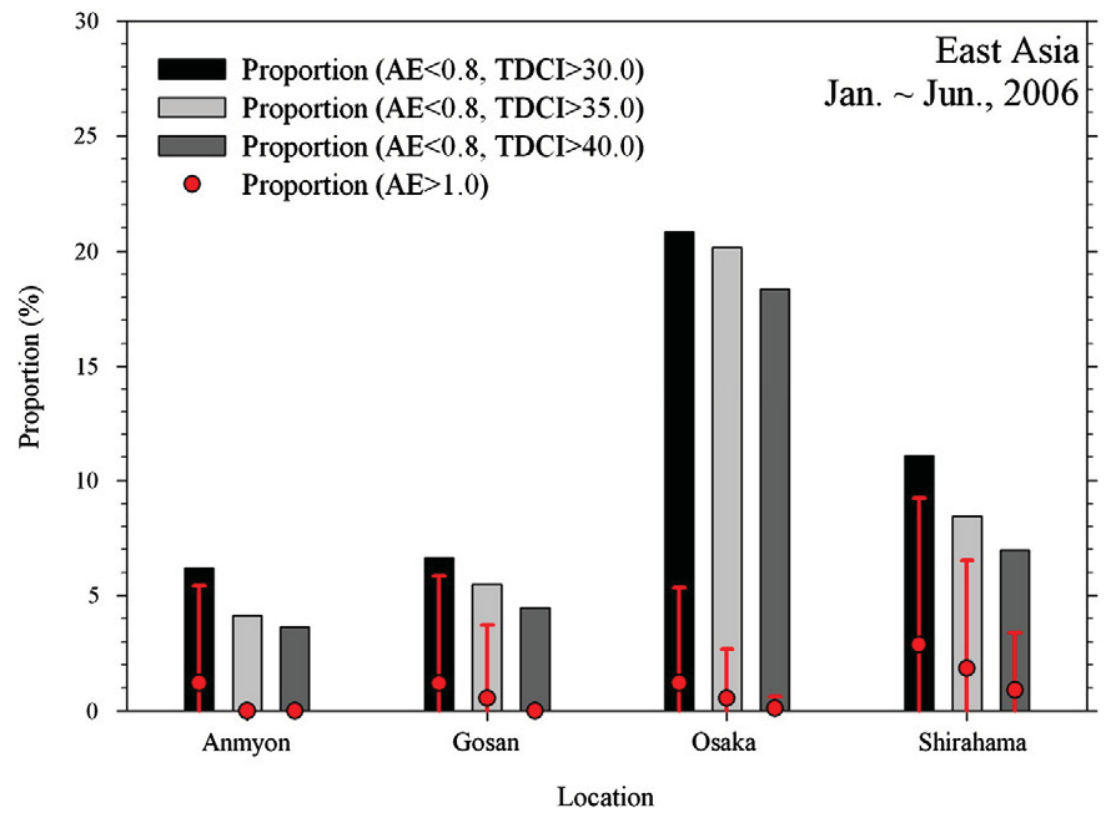

Fig. 13. The mean proportion of dust pixels from the IR algorithm around AERONET sites for AE from AERONET lower than 0.8 and higher than 1.0 . 
Table 5

Location of AERONET sites.

\begin{tabular}{lcc}
\hline AERONET site & \multicolumn{2}{c}{ Location } \\
\cline { 2 - 3 } & Latitude (degree) & Longitude (degree) \\
\hline Anmyon & $36.54^{\circ} \mathrm{N}$ & $126.33^{\circ} \mathrm{E}$ \\
Gosan & $33.29^{\circ} \mathrm{N}$ & $126.16^{\circ} \mathrm{E}$ \\
Osaka & $34.65^{\circ} \mathrm{N}$ & $135.59^{\circ} \mathrm{E}$ \\
Shirahama & $33.69^{\circ} \mathrm{N}$ & $135.36^{\circ} \mathrm{E}$ \\
\hline
\end{tabular}

in a $0.5^{\circ} \times 0.5^{\circ}$ grid centered at each AERONET site. The spatial scale of the dust plume is typically on the order of at least $10 \mathrm{~km}$, so the dust proportion value is expected to increase for the dust condition. For the dust-laden case determined by AERONET, the mean proportions of dust pixels from the IR algorithm are higher than the upper one standard deviation of the proportions for the non-dust case (defined by $\mathrm{AE}>1.0$ and $\mathrm{AOT}>0.4$ ) at four different locations. Therefore, the IR algorithm shows statistical significance for dust detection.

\section{Summary \& conclusion}

A combined dust detection algorithm is developed by using the MODIS IR bands. Because the BTs by IR bands are influenced by cloud, water vapor, surface type, and sulfur dioxide, the algorithm is developed by the combination of several dust detection methods, including the $\operatorname{BTD}(11-12), \operatorname{BTR}(11 / 12), \operatorname{BTR}(11 / 8.6)$ and $\mathrm{D}^{*}$ method, as well as the newly introduced C-BTR method. The $\mathrm{BTD}(11-12)$ method detects dust as negative values of BTD(11-12). Two C-BTR methods use the 30-day composite of the BTR based on the maximum BT(11) to determine the surface property. The $\mathrm{D}^{*}$ method uses three bands to distinguish between dust and cirrus signals as suggested by Hansell et al. (2007). To minimize error due to cloud contamination, the current algorithm includes three methods for cloud masking, BT(11), $\mathrm{R}^{2}(7.3-11)$, and BT(11) variation. Each dust detection method calculates the DCI value, which serves as a confidence index for dust detection. After each DCI calculation, the TDCI as a mean value of all of the DCIs is suggested as the final detection result

The results of the IR algorithm for two dust events on March 11 and April 8, 2006 are compared with shortwave algorithms, i.e. FMF from MODIS, AI from OMI, and the MOA. The agreement ranges from 0.405 to 0.969 , from 0.648 to 0.745 , and from 0.892 to 0.973 between the current IR algorithm and the FMF, AI, and MOA, respectively. These statistical results show that the IR algorithm successfully observes the dust plume from several dust cases over East Asia.

For long-term validation of the IR algorithm, the agreement ranges from 0.643 to 0.814 , and from 0.724 to 0.750 compared with the FMF with $\mathrm{AOD}>1.0$, and the MOA with AOD $>1.25$ as a reference, respectively. For the low AOD case, inconsistency between the IR algorithm and the shortwave algorithms is estimated because of the weak sensitivity of the IR algorithm and errors in the aerosol size parameter from the shortwave algorithm. Compared with the AI, the agreement ranges from 0.601 to 0.668 over the non-polluted land region, while it ranges from 0.309 to 0.403 over East Asia. The difference in the agreement can be attributed to the mixture of different anthropogenic aerosols over East Asia. Furthermore, the false detection of the current result is lower than that of the BTD(11-12) by taking the surface conditions into consideration. Compared with the AERONET data, a high value of the TDCI region is observed more frequently in the case of the low $\mathrm{AE}$ observed by the AERONET at four stations over East Asia. It can be concluded that the current IR algorithm is able to clearly define dust regions over land and ocean. This study compares the results during daytime scenes as the reference results are based on the UV and visible wavelength range. Therefore, the validation with active sensors (i.e. CALIPSO) during nighttime scenes is planned for future study.

\section{Acknowledgment}

This research was supported by the Eco Innovation Program of KEITI Korea (ARQ201204015). The authors express their thanks to the principal investigators and their staff for establishing and maintaining the AERONET and MODIS sites used in this study. SSP, JK and JHL received partial support from the Brain Korea 21 (BK21) program.

\section{References}

Ackerman, S. A. (1997). Remote sensing aerosols using satellite infrared observations. Journal of Geophysical Research, 102(D14), 17,069-17,079.

Ackerman, S. A., Strabala, K. I. Menzel, W. P., Frey, R. A., Moeller, C. C., \& Gumley, L. E. (1998). Discriminating clear sky from clouds with MODIS. Journal of Geophysical Research, 103(D24), 32,141-32,157.

Ackerman, S. A., Strabala, K. I., Menzel, W. P., Frey, R., Moeller, C., Gumley, L., et al. (2002) Discriminating clear-sky from cloud with MODIS algorithm theoretical basis document (MOD35). ATBD Ref. ATBD-MOD-06, version 4.0, 115 pp. Greenbelt, MD: NASA Goddard Space Flight Center.

Baddock, M. C., Bullard, J. E., \& Bryant, R. G. (2009). Dust source identification using MODIS: A comparison of techniques applied to the Lake Eyre Basin, Australia. Remote Sensing of Environment, 113, 1511-1528.

Caquineau, S., Gaudicet, A., Gomes, L., \& Legrand, M. (2002). Mineralogy of Saharan dust transported over northwestern tropical Atlantic Ocean in relation to source regions. Journal of Geophysical Research, 107(D15), 4251. http://dx.doi.org/10.1029/ 2000JD000247.

Chen, Y., Sun-Mack, S., Minnis, P., Young, D. F., \& Smith, W. L., Jr. (2002). Surface spectral emissivity derived from MODIS data. Proc. SPIE 3rd Intl. Asia-Pacific Environ. Remote Sensing Symp.: Remote Sens. of Atmos., Ocean, Environment, and Space (pp. 23-27).

Chomette, O., Legrand, M., \& Marticorena, B. (1999). Determination of the wind speed threshold for the emission of desert dust using satellite remote sensing in the thermal infrared. Journal of Geophysical Research, 104(D24), 31,207-31,215.

Chu, D. A., Remer, L. A., Kaufman, Y. J., Schmid, B., Redemann, J., Knobelspiesse, K., et al. (2005). Evaluation of aerosol properties over ocean from Moderate Resolution Imaging Spectroradiometer (MODIS) during ACE-Asia. Journal of Geophysical Research, 110, D07308. http://dx.doi.org/10.1029/2004JD005208.

Darmenov, A., \& Sokolik, I. N. (2005). Identifying the regional thermal-IR radiative signature of mineral dust with MODIS. Geophysical Research Letters, 32, L16803. http://dx.doi.org/10.1029/2005GL023092.

Darmenova, K., Sokolik, I. N., \& Darmenov, A. (2005). Characterization of east Asian dust outbreaks in the spring of 2001 using ground-based and satellite data. Journal of Geophysical Research, 110, D02204. http://dx.doi.org/10.1029/2004JD004842

De Paepe, B., \& Dewitte, S. (2009). Dust aerosol optical depth over a desert surface using the SEVIRI window channels. Journal of Atmospheric and Oceanic Technology, 26, 704-718. http://dx.doi.org/10.1175/2008JTECHA1109.1.

Elachi, C., \& van Zyl, J. (2006). Introduction to the physics and techniques of remote sensing. USA: John Wiley \& Sons Inc.

Gangale, G., Prata, A. J., \& Clarisse, L. (2010). The infrared spectral signature of volcanic ash determined from high-spectral resolution satellite measurements. Remote Sensing of Environment, 114, 414-425.

Hansell, R. A., Ou, S.C., Liou, K. N., Roskovensky, J. K., Tsay, S.C., Hsu, C., et al. (2007). Simultaneous detection/separation of mineral dust and cirrus clouds using MODIS thermal infrared window data. Geophysical Research Letters, 34, L11808. http://dx.doi.org/10.1029/2007GL029388.

Herman, J. R., Bhartia, P. K., Torres, O., Hsu, C., Seftor, C., \& Celarier, E. (1997). Global distribution of UV-absorbing aerosols from Nimbus 7/TOMS data. Journal of Geophysical Research, 102(D14), 16,911-16,922.

Holben, B. N., Eck, T. F., Slutsker, I., Tanre, D., Buis, J. P., \& Setzer, A. (1998). AERONET a federated instrument network and data archive for aerosol characterization. Remote Sensing of Environment, 66, 1-16.

Hsu, N. C., Tsay, S., King, M.D., \& Herman, J. R. (2004). Aerosol properties over bright-reflecting source regions. IEEE Trans. Geosci. Remote, 42(3), 557-569.

Hudson, P. K., Gibson, E. R., Young, M.A., Kleiber, P. D., \& Grassian, V. H. (2008). Coupled infrared extinction and size distribution measurements for several clay components of mineral dust aerosol. Journal of Geophysical Research, 113, D01201. http://dx.doi.org/10.1029/2007JD008791.

Iino, N., Kinoshita, K., Tupper, A.C., \& Yano, T. (2004). Detection of Asian dust aerosols using meteorological satellite data and suspended particulate matter concentrations. Atmos. Environ., 38, 6999-7008.

Jeong, M., \& Li, Z. (2005). Quality, compatibility, and synergy analyses of global aerosol products derived from the advanced very high resolution radiometer and total ozone mapping spectrometer. Journal of Geophysical Research, 110, D10S08. http://dx.doi.org/10.1029/2004JD004647.

Kim, J., Lee, J., Lee, H. C., Higurashi, A., Takemura, T., \& Song, C. H. (2007). Consistency of the aerosol type classification from satellite remote sensing during the Atmospheric Brown Cloud-East Asia Regional Experiment campaign. Journal of Geophysical Research, 112, D22S33. http://dx.doi.org/10.1029/2006JD008201.

Lee, J., Kim, J., Lee, H. C., \& Takemura, T. (2007). Classification of aerosol type from MODIS and OMI over East Asia. J. Korean Meteorol. Soc., 43(4), 343-357.

Lee, J., Kim, J., Song, C. H., Ryu, J. -H., Ahn, Y. -H., \& Song, C. K. (2010). Algorithm for retrieval of aerosol optical properties over the ocean from the Geostationary Ocean Color Imager. Remote Sensing of Environment, 114, 1077-1088. 
Lee, J., Kim, J., Yang, P., \& Hsu, N. C. (2012). Improvement of aerosol optical depth retrieval from MODIS spectral reflectance over the global ocean using new aerosol models archived from AERONET inversion data 4 and tri-axial ellipsoidal dust database data. Atmospheric Chemistry and Physics, 12, 7087-7102. http://dx.doi.org/10.5194/acp-12-7087-2012.

Levy, R. C., Remer, L. A., Mattoo, S., Vermote, E. F., \& Kaufman, Y. J. (2007). Second-generation operational algorithm: Retrieval of aerosol properties over land from inversion of Moderate Resolution Imaging Spectroradiometer spectral reflectance. Journal of Geophysical Research, 112, D13211. http://dx.doi.org/10.1029/2006JD007811.

Levy, R. C., Remer, L. A., Tanre, D., Mattoo, S., \& Kaufman, Y. J. (2009). Algorithm for remote sensing of tropospheric aerosol over dark target from MODIS: Collections 005 and 051 Revision 2.

Martins, J. V., Tanre, D., Remer, L. A., Kaufman, Y. J., Mattoo, S., \& Levy, R. (2002). MODIS cloud screening for remote sensing of aerosol over oceans using spatial variability. Geophysical Research Letters, 29, 8009. http://dx.doi.org/10.1029/2001GL013252.

Merchant, C. J., Embury, O., Le Borgne, P., \& Bellec, B. (2006). Saharan dust in nighttime thermal imagery: Detection and reduction of related biases in retrieved sea surface temperature. Remote Sensing of Environment, 104, 15-30.

Miller, S. D. (2003). A consolidated technique for enhancing desert dust storms with MODIS. Geophysical Research Letters, 30(20), 2071. http://dx.doi.org/10.1029/2003GL018279.

Pierangelo, C., Chedin, A., Heilliette, S., Jacquinet-Husson, N., \& Armante, R. (2004). Dust altitude and infrared optical depth from AIRS. Atmospheric Chemistry and Physics, $4,1813-1822$

Prata, A. J. (1989). Observations of volcanic ash clouds in the 10-12 um window using AVHRR/2 data. International Journal of Remote Sensing, 10, 751-761.

Prospero, J. M., Ginoux, P., Torres, O., Nicholson, S. E., \& Gill, E. (2002). Environmental characterization of global sources of atmospheric soil dust identified with the NIMBUS 7 Total Ozone Mapping Spectrometer (TOMS) absorbing aerosol product. Reviews of Geophysics, 40, 1.

Remer, L. A., Kaufman, Y. J., Tanre, D., Mattoo, S., Chu, D. A., \& Martins, J. V. (2005) The MODIS aerosol algorithm, products and validation. Journal of the Atmospheric Sciences, 62, 947-973.

Remer, L. A., Tanre, D., Kaufman, Y. J., Ichoku, C., Mattoo, S., Levy, R., et al. (2002) Validation of MODIS aerosol retrieval over ocean. Geophysical Research Letters, 29(12). http://dx.doi.org/10.1029/2001GL013204.

Roskovensky, J. K., \& Liou, K. N. (2005). Differentiating airborne dust from cirrus clouds using MODIS data. Geophysical Research Letters, 32, L12809. http://dx.doi.org/10.1029/2005GL022798.
Salisbury, J. W., \& Wald, A. (1992). The role of volume scattering in reducing spectral contrast of reststrahlen bands in spectra of powdered minerals. Icarus, 96, 121-128.

Seemann, S. W., Borbas, E. E., Knuteson, R. O., Stephenson, G. R., \& Huang, H. -L. (2008). Development of a global infrared land surface emissivity database for application to clear sky sounding retrievals from multispectral satellite radiance measurements. Journal of Applied Meteorology and Climatology, 47, 108-123.

Shenk, W. E., \& Curran, R. J. (1974). The detection of dust storms over land and water with satellite visible and infrared measurement. Monthly Weather Review, 102, 830-837.

Sokolik, I. N., \& Toon, O. B. (1999). Incorporation of mineralogical composition into models of the radiative properties of mineral aerosol from UV to IR wavelengths. Journal of Geophysical Research, 104(D8), 9423-9444.

Sokolik, I. N., Toon, O. B., \& Bergstrom, R. W. (1998). Modeling the radiative characteristics of airborne mineral aerosols at infrared wavelengths. Journal of Geophysical Research, 103(D8), 8813-8826.

Tang, B., \& Li, Z. -L. (2008). Estimation of instantaneous net surface longwave radiation from MODIS cloud-free data. Remote Sens. Environ., 112, 3482-3492.

United States Committee on Extension to the Standard Atmosphere (1976). US Standard Atmosphere 1976. Washington DC, USA: National Oceanic and Atmospheric Administration, NASA, United States Air Force.

Wald, A. E., Kaufman, Y. J., Tanre, D., \& Gao, B. -C. (1998). Daytime and nighttime detection of mineral dust over desert using infrared spectral contrast. Journal of Geophysical Research, 103, 32,307-32,313.

Wald, A. E., \& Salisbury, J. W. (1995). Thermal infrared directional emissivity of powdered quartz. Journal of Geophysical Research, 100(B12), 24,665-24,675.

Wang, M., \& Lu, D. (2006). Diurnal and seasonal variation of clear-sky land surface temperature of several representative land surface types in china retrieved by GMS-5. Acta Meteorol. Sin., 20(4), 475-488.

Watson, I. M., Realmuto, V. J., Rose, W. I., Prata, A. J., Bluth, G. J. S., Gu, Y., et al. (2004) Thermal infrared remote sensing of volcanic Emissions using the Moderate Resolution Imaging Spectroradiometer. J. Volcanol. Geoth. Res., 135, 75-89.

Wenrich, M. L., \& Christensen, P. R. (1996). Optical constants of minerals derived from emission spectroscopy: Application to quartz. Journal of Geophysical Research, 101(B7), 15,921-15,931.

Zhang, J., Reid, J. S., \& Holben, B. N. (2005). An analysis of potential cloud artifacts in MODIS over ocean aerosol optical thickness products. Geophysical Research Letters, 32, L15803. http://dx.doi.org/10.1029/2005GL023254. 